\title{
Optimal orientation of fibre composites for strength based on Hashin's criteria optimality conditions
}

\author{
Rafael T. L. Ferreira ${ }^{1}$ (D) - Ian A. Ashcroft ${ }^{2}$ \\ Received: 11 July 2019 / Revised: 16 October 2019 / Accepted: 20 November 2019 / Published online: 19 February 2020 \\ (C) The Author(s) 2020
}

\begin{abstract}
The Hashin's strength criteria are usually employed in first ply failure and damage-onset analysis of fibre-reinforced composites. This work presents optimality conditions of local material orientations for these criteria, in terms of principal stresses and material strength parameters. Each criterion (matrix tensile/compressive, fibre tensile/compressive modes) has its conditions separately derived, analytically, based on a fixed stress field assumption. The conditions found show that orientations which coincide and do not coincide with principal stress directions may minimise local failure indices. These solutions are employed in a proposed algorithm, named HA-OCM (Hashin Optimality Criteria Method), which selectively satisfies the matrix failure modes (either tensile or compressive), iteratively and finite element-wise in composites. It is demonstrated that the HA-OCM is able to design single-layer plane structures with improved failure loads in comparison with designs following only maximum (in absolute) principal stress orientations. Results show that the material orientations have a trend to end up either aligned or at $90^{\circ}$ with maximum in absolute principal stress directions. Global optima for compliance are, however, not guaranteed. To give an idea of gains in terms of failure loads, some HA-OCM designs show improvements of $71 \%$ and $140 \%$, for example, in comparison with principal stress design.
\end{abstract}

Keywords Fibre composites orientation for strength · Hashin's strength criteria · Optimality conditions · Optimisation algorithm

\section{Introduction}

Fibre-reinforced polymers are composite materials (Jones 1998; Barbero 2010) which enable structures with high specific stiffness and strength. Their utilisation is well established in several industrial fields, including aerospace, automotive, naval and sport equipment. These composites are usually employed in laminates designed in terms of stacking sequences, which are defined by layer number and thickness, materials and fibre orientations. These parameters can be seen as design variables which may

\footnotetext{
Responsible Editor: Ji-Hong Zhu

Rafael T. L. Ferreira

rthiago@ita.br

1 GPMA, Research Group on Additive Manufacturing, Instituto Tecnólogico de Aeronáutica, DCTA ITA IEM, 12228-900, São José dos Campos, São Paulo, Brazil

2 CfAM, Centre for Additive Manufacturing, Faculty of Engineering, University of Nottingham, NG8 1BB, Nottingham, UK
}

assume many distinct values. Their combinations lead to an enormous number of design possibilities, hence optimisation techniques which help in selecting the best designs are useful tools, enabling a reduction in time, effort and resources.

Optimisation methodologies can be used to tailor composites to specific structural requirements, for example stiffness (Foldager et al. 1998; Lund and Stegmann 2005; Setoodeh et al. 2006; Ferreira et al. 2014; Ferreira and Hernandes 2015; Muramatsu and Shimoda 2019), strength (Schmit and Farshi 1973; Fukunaga and Vanderplaats 1991; Groenwold and Haftka 2006; Lund 2017), buckling load (Hu 1994; Lindgaard and Lund 2011; Kaveh et al. 2019), natural frequency (Abdalla et al. 2007; Karakaya and Soykasap 2011; Koide and Luersen 2013) and layer delamination (Hohe and Becker 2002; Ferreira et al. 2011). An optimisation process can be classified as constant stiffness design, which according to Ghiasi et al. (2009) deals with composite laminates with a uniform stacking sequence throughout the entire structure, or variable stiffness design (Ghiasi et al. 2010), where the stacking sequence varies through the structural domain. 
Fibre orientations strongly influence the structural response of polymer-fibre composites. As fibres are much stiffer than the matrix, their reinforcement direction is stiffer/stronger than other directions, leading to anisotropic behaviour. Therefore, material orientations are often seen as design variables in optimisation problems for fibre-reinforced composites (Ghiasi et al. 2009, 2010; Nicoloso 2018). Examples of variable stiffness design in terms of fibre orientation are composites with steered fibre paths, where such orientations vary in the structure. Variable stiffness design for orientations is here further classified as either pointwise design or curve-based design, as described below.

In point-wise design, the composite material has fibre orientations independently designed in certain areas (design domains) of a structure, e.g. when these orientations are optimised at every finite element of a numerical model. Design parametrisations used in point-wise design are, for instance parametrisation directly in material orientation (albeit this is generally avoided in view of the many local minima (Foldager et al. 1998)), in lamination parameters, as employed in Setoodeh et al. (2006), the DMO (discrete material optimisation) method (Lund and Stegmann 2005; Lund 2009, 2017) and its further variations SFP (shape functions with penalisation) (Brüyneel 2011) and BCP (bi-value coded parametrisation) (Gao et al. 2012). Other examples are element-wise principal strain/stress design (Pedersen 1989; Malakhov and Polilov 2016), the discrete orientation selection method based on a normal distribution selection function plus a filter for fibre continuity in Kiyono et al. (2017), and distributed-parameter orientation optimisation based on the $H^{1}$ gradient method in Muramatsu and Shimoda (2019).

In curve-based design, the composite material has fibre orientations designed following parametrised curves, whose optimised shapes dictate variable orientations throughout a structure. Examples are fibre-path optimisation by using level-set methods (Brampton et al. 2015; Lemaire et al. 2015), the B-spline parametrisation in Montemurro and Catapano (2017), the fluid stream line parametrisation in Yamanaka et al. (2016) and the parametrised curve family in Zhu et al. (2017), which mimic principal stress trajectories. In general, curve-based design delivers more productionready results, while point-wise design usually needs postprocessing to translate the results to fibre paths that may be production-feasible. However, point-wise design provides greater design freedom, whose results can be inclusive employed in proposing adequate curve shapes for parametrisation in curve-based design.

Common composite production technologies, such as material hand layup and RTM (resin transfer moulding) (Dai and Hahn 2003; Magagnato et al. 2018), have limitations in terms of delivering structures of variable stiffness design, since it is practically impossible to implement steered fibre paths with them. However, technologies such as AFP (automated fibre placement) (Lukaszewicz et al. 2012; Woigk et al. 2018), ATL (automated tape laying) (Sloan J 2008) and more recently FFF (fused filament fabrication), a type of additive manufacturing (often also referred to as 3D printing) (Nicoloso 2018; Matsuzaki et al. 2016; Ferreira et al. 2017; Dickson et al. 2017; Yang et al. 2017; Wang et al. 2017; Zhuo et al. 2017; Dutra et al. 2019), have increased production flexibility in terms of curvilinear fibre reinforcements.

AFP and ATL have already reached the maturity to be used in industry and build primary structural final components, while FFF for composites is still under development. Challenges to be overcome include the low material stiffness/strength in comparison with traditional composites (typical values can be seen in Table 1 in Section 4), allowable size of the parts produced, due to the still small build envelopes of typical 3D printers, and production time, which can be very high for intricate/complex components. Moreover, draping phenomena (Boisse et al. 2007; Cherouat et al. 2005) may also be of concern, as seen with variable stiffness designs in general. However, FFF processes have the potential to reproduce finer design details, more complex fibre path shapes due to increased fibre curvature freedom, and present a much finer fibre-path width resolution (deposition width in the order of tenths of $\mathrm{mm}$ ), in

Table 1 Mechanical properties of unidirectional fibre reinforced composite materials

\begin{tabular}{llll}
\hline & $\begin{array}{l}\text { Carbon-epoxy }^{\mathrm{a}} \\
(\mathrm{CF})\end{array}$ & $\begin{array}{l}\text { Glass-epoxy }^{\mathrm{b}} \\
(\mathrm{GF})\end{array}$ & $\begin{array}{l}\text { Carbon-nylon }^{\mathrm{c}} \\
(3 \mathrm{DCF})\end{array}$ \\
\hline Strength [MPa] & & & \\
$X_{t}$ & 1500 & 1140 & 493.9 \\
$X_{c}$ & 900 & 570 & 323.9 \\
$Y_{t}$ & 27 & 35 & 13.5 \\
$Y_{c}$ & 200 & 114 & 20.25 \\
$S_{12}$ & 80 & 72 & 35 \\
$S_{23}{ }^{\mathrm{d}}$ & 42.426 & 36.469 & 8.482 \\
Stiffness [GPa] $_{\text {iiff }}$ & & & \\
$E_{11}$ & 138 & 53.48 & 50 \\
$E_{22}$ & 11 & 17.7 & 2.322 \\
$G_{12}=G_{13}$ & 5.50 & 5.83 & 0.624 \\
$G_{23}$ & 3.928 & 6.321 & 0.581 \\
Poisson ratios & & & \\
$v_{12}$ & 0.280 & 0.278 & 0.333 \\
$\nu_{23}$ & 0.400 & 0.400 & - \\
\hline
\end{tabular}

${ }^{a}$ Soden et al. (1998) Carbon fibre T300 and epoxy matrix;

${ }^{\mathrm{b}}$ Soden et al. (1998) E Glass Gevetex fibre and epoxy matrix;

${ }^{c}$ Dutra et al. (2019) and Ferreira et al. (2018) 3D printed carbon fibre and nylon matrix;

${ }^{\mathrm{d}}$ Estimated as in Christensen (2014). 
comparison with both AFP and ATL. The capabilities of all these technologies motivate the development of design optimisation techniques for variable stiffness design.

In this work, focus is given to variable stiffness, pointwise design for fibre orientation, aiming to improve the strength of single-layered composite structures evaluated according to the Hashin failure criteria (Hashin 1980), by means of optimality conditions (OC). It is proposed that the optimised designs obtained may be employed to indicate improved fibre paths that may not be gained from standard composite design methods. However, as no manufacturing constraints are taken into account, a further step in considering the best method to realise the improved design within the context of current manufacturing constraints would be needed.

In the literature, the problem of finding local orientations of orthotropic materials for stiffness maximisation has known optimality conditions (Pedersen 1989; Seregin and Troitskii 1981; Rovati and Taliercio 1991), which are associated with minimum levels of global strain energy and/or compliance. The results obtained using this approach by Pedersen in Pedersen (1989) and further explored in Pedersen $(1990,1991)$ show that aligning principal material axes with the axes of principal strains maximises stiffness, for a material with relatively low shear stiffness (weak in shear according to the terminology in Pedersen (1989)). This condition was developed to design local material orientations in 2D structures. Moreover, at the optimum according to these $\mathrm{OC}$, the axes of principal strains and principal stresses coincide in view of material orthotropy. Therefore, co-alignment (Ghiasi et al. 2010) of principal stress/strain directions with material principal directions can be used for stiffness maximisation. However, if the material is strong is shear (still as defined in Pedersen (1989)), other solutions may be found, e.g. as in Ferreira et al. (2014).

Designing for optimum strength, in contrast, is based on local measurements whose evaluation relies on criteria which are not unique. For fibre-reinforced composites, examples of strength metrics commonly employed are the Tsai-Hill (1965), Tsai-Wu (1971), Hashin (1980) and Puck and Schürmann (1998) criteria. An approach for strength maximisation is to minimise such criteria at the most critical points of the structure, as pointed out in Pedersen (2004). If the strength criterion adopted is the local strain energy density, then the minimisation of the maximum strength measurement (i.e. at the most damaged point) in a structural domain is obtained by designs of uniform strain energy density over all its points, as shown in Pedersen (1998) (in view of Taylor (1969) and Masur (1970)). This is an optimality condition well known for stiffness maximisation, e.g. as recognised in topology optimisation problems (Bendsøe and Sigmund 2003). Therefore, for the strain energy density strength criteria, the stiffest structure is also the strongest. When other criteria are employed, this condition is not guaranteed.

In practice, design for principal stresses (meaning fibre direction alignment with principal stress directions) has been successfully employed in improving the strength of fibre composites, which may be associated to shear stress reductions, e.g. as in Zhu et al. (2017), Hyer and Charette (1987), Kriechbaum et al. (1992), Reuschel and Mattheck (1999), Tosh and Kelly (2000), and Crosky et al. (2006). Work on optimum design problems for material orientations that formally take strengths into account can also be found in the literature (Fukunaga and Vanderplaats 1991; Groenwold and Haftka 2006; Hammer and Pedersen 1996; Park et al. 2001; Kathiravan and Ganguli 2007; Topal and Uzman 2008). The basic approach in these papers was to select appropriate failure criteria, formulate a problem which take these criteria into account and then solve it using numerical optimisation methods. A few studies have considered optimality conditions. For instance, the OC for fibre orientation in terms of the Hill and Tsai-Wu criteria were derived for 2D and 3D cases in Majak and Hannus (2003). The results show that orientations other than those of principal stresses can minimise the criteria, depending on material properties and loadings. Similar conclusions were found in Brandmaier (1970), where optimal orientations for Hill's criterion were analytically derived and studied for a graphite-epoxy composite. Optimal orientation for 3D orthotropic materials was studied in Majak and Pohlak (2010) by evaluating the OC of Hill's strength criteria with respect to Euler angles, using a formulation in terms of strains, whose solutions were validated using genetic programming. However, these studies failed to demonstrate practical optimisation algorithms based on the derived OC.

The contribution of the present paper is to analytically derive optimality conditions for minimisation of Hashin's failure criteria (matrix tensile/compressive and fibre tensile/compressive) (Hashin 1980), for local material orientations, in terms of principal stresses and strength material parameters. Moreover, this work aims to devise a simple point-wise optimisation algorithm based on these OC, which improves the strength of single-layered fibre composite structures. The OC are derived under a fixed stress field assumption, for the case of 2D plane stress, and principal stress directions are used as reference. OC results show that material orientations which coincide and do not coincide with principal stress directions may locally minimise the studied strength criteria. The developed optimisation scheme, named HA-OCM (Hashin Optimality Criteria Method), is based on iteratively satisfying the $\mathrm{OC}$ of matrix failure criteria (either tensile or compressive), finite element-wise in composite structures. This aspect highlights that Hashin's criteria can be separately satisfied in order to tailor a material orientation field in a structure according 
to specific necessities. Results of the HA-OCM method show that failure loads of the optimal structures obtained are raised in comparison with others designed by principal stress design. Final results will be commented in terms of $\mathrm{OC}$ for stiffness maximisation.

From the next section, this paper is organised as follows: Section 2 shows basic equations of Hashin's failure criteria and employed stress transformation relations; Section 3 presents the derived OC for Hashin's failure criteria with respect to material orientation and in terms of material strength parameters and principal stresses; Section 4 introduces the HA-OCM optimisation method; Section 5 details HA-OCM results, which render structures of improved strength; and Section 6 shows summary and conclusion. Furthermore, Appendix A features a summary of OC results from Section 3 and Appendix B shows a summary of compliance benchmark OC from the literature (Pedersen 1989, 1990).

\section{Hashin's failure criteria}

Hashin's failure criteria (Hashin 1980) are considered in this paper as a basis for defining an OC for fibre orientation. These failure criteria are developed based on hypotheses built on observed failure modes of composites, a concept also explored in the Hashin-Roten criteria (Hashin and Rotem 1973; París 2001). Each criterion governs a distinct failure mode: matrix tensile, matrix compressive, fibre tensile and fibre compressive. They interact in terms of stresses and strength properties, and are well established in measuring fibre composite first ply failure and/or damage onset (Zhu et al. 2017; Koh and Madsen 2018; de Miguel et al. 2018; Li et al. 2019; Kim and Kim 2019; Joosten 2019).

A deformable solid of orthotropic material under plane stress is considered. For the case of composites with polymeric matrix and unidirectional fibre reinforcement, local material orientations can be defined as follows: 1 , the fibre reinforcement direction (in which composite equivalent properties are fibre dominated); 2 , a direction perpendicular to 1 ( 2 is referred to as the matrix direction since equivalent properties are matrix dominated). Pointwise stresses are defined as follows: $\sigma_{11}$, the direct stress component in $1 ; \sigma_{22}$ the direct stress component in 2 ; and $\tau_{12}$, the shear stress component on plane 1-2. In this case, the four equations of Hashin's failure criteria (Hashin 1980) under plane stress are shown in (1), (2), (3) and (4).

When $\sigma_{22}>0$, failure occurs according to the matrix tensile (MT) mode if:

$F^{Y t}=\left(\frac{\sigma_{22}}{Y_{t}}\right)^{2}+\left(\frac{\tau_{12}}{S_{12}}\right)^{2}=1$.
When $\sigma_{22}<0$, failure occurs according to the matrix compressive (MC) mode if:

$F^{Y c}=\left(\frac{\sigma_{22}}{2 S_{23}}\right)^{2}+\left[\left(\frac{Y_{c}}{2 S_{23}}\right)^{2}-1\right] \frac{\sigma_{22}}{Y_{c}}+\left(\frac{\tau_{12}}{S_{12}}\right)^{2}=1$.

When $\sigma_{11}>0$, failure occurs according to the fibre tensile (FT) mode if:

$F^{X t}=\left(\frac{\sigma_{11}}{X_{t}}\right)^{2}+\left(\frac{\tau_{12}}{S_{12}}\right)^{2}=1$.

Finally, when $\sigma_{11}<0$, failure occurs according to the fibre compressive (FC) mode if:

$$
F^{X c}=\frac{\sigma_{11}}{-X_{c}}=1 \text {. }
$$

In (1) to (4), strength material properties are assumed as follows: $X_{t}$ and $X_{c}$ are respectively the tensile and compressive strengths in direction 1 (fibre); $Y_{t}$ and $Y_{c}$ are respectively the tensile and compressive strengths in direction 2 (matrix); $S_{12}$ is the in-plane shear strength and $S_{23}$ is an out-of-plane shear strength.

\subsection{Local 1-2 stresses in terms of principal stresses}

The well-known relations for plane stress rotational transformations (Kelly 2015) can be written as:

$\sigma_{11}=\frac{1}{2}\left[\left(\sigma_{1 p}+\sigma_{2 p}\right)+\left(\sigma_{1 p}-\sigma_{2 p}\right) \cos 2 \beta\right]$,

$\sigma_{22}=\frac{1}{2}\left[\left(\sigma_{1 p}+\sigma_{2 p}\right)-\left(\sigma_{1 p}-\sigma_{2 p}\right) \cos 2 \beta\right]$,

$\tau_{12}=-\frac{1}{2}\left(\sigma_{1 p}-\sigma_{2 p}\right) \sin 2 \beta$.

In (5), (6) and (7), the local stresses $\sigma_{11}, \sigma_{22}$ and $\tau_{12}$ are written in terms of principal stresses $\sigma_{1 p}$ and $\sigma_{2 p}$, assumed $\left|\sigma_{1 p}\right|>\left|\sigma_{2 p}\right|$, and $\beta$, which is an orientation measured from the principal stress $\sigma_{1 p}$ direction to the local material direction 1 . The objective of the formulation in the next section is to find the optimal value of $\beta$ by minimizing each of the Hashin's failure criteria.

\section{Optimality of Hashin's criteria}

In this section, the optimality conditions (OC) of Hashin's failure criteria are derived in terms of point-wise local material orientations, having as reference the principal stress directions. $\beta$ from (5) to (7) governs material orientation in a small design region of a structure, with many such regions over the structure, as in variable stiffness design. A fixed stress field hypothesis is followed, which means it is assumed that the stress field in the whole deformable solid 
is not sensitive to changes in point-wise local material orientations. This is a simplified assumption, since it is known that the stress field is prone to change in this case (Pedersen 1989, 1990). However, this assumption guarantees the analytical solution of the presented OC, whose results are used in the iterative optimisation method presented in Section 4. It is considered that this method will converge to a design point where the fixed stress field assumption has little effect on the optimised material orientations, as seen in Pedersen (1990). Further comments on this aspect of criterion sensitivities are made in Section 3.5.

\subsection{Matrix tensile failure criterion}

\subsubsection{Derivation of optimality conditions}

Rewriting (1) in terms of principal stresses $\left|\sigma_{1 p}\right|>\left|\sigma_{2 p}\right|$ and orientation $\beta$, in view of (6) and (7), renders:

$$
\begin{aligned}
F^{Y t}(\beta)= & \frac{1}{4 Y_{t}^{2}}\left[\sigma_{1 p}+\sigma_{2 p}-\cos 2 \beta\left(\sigma_{1 p}-\sigma_{2 p}\right)\right]^{2} \\
& +\frac{1}{4 S_{12}^{2}} \sin ^{2} 2 \beta\left(\sigma_{1 p}-\sigma_{2 p}\right)^{2} .
\end{aligned}
$$

This failure mode is evaluated when $\sigma_{22}>0$. To minimise this criterion, the following problem in standard form is stated:

$$
\begin{array}{ll}
\underset{\beta}{\operatorname{minimise}} & F^{Y t}(\beta) \\
\text { subject to: } & g_{a}=-\sigma_{22}(\beta) \leq 0 .
\end{array}
$$

In the problem of (9), $F^{Y t}$ is the objective function to be minimised in $\beta$ and $g_{a} \leq 0$ is a standard inequality constraint. Considering the Lagrange multiplier $\lambda_{a}$, the Lagrangian function $L_{Y t}$ for the problem in (9) is written as:

$$
L_{Y t}\left(\beta, \lambda_{a}\right)=F^{Y t}(\beta)-\lambda_{a} \sigma_{22}(\beta) \text {. }
$$

The first-order necessary conditions for $L_{Y t}\left(\beta, \lambda_{a}\right)$ at stationary points (where $\beta=\beta^{*}$ ) are:

$$
\begin{aligned}
& \left.\frac{\partial L_{Y t}}{\partial \beta}\right|_{\beta^{*}}=\frac{\partial F^{Y t}}{\partial \beta}-\lambda_{a} \frac{\partial \sigma_{22}}{\partial \beta}=0, \\
& \left.\frac{\partial L_{Y t}}{\partial \lambda_{a}}\right|_{\beta^{*}}=-\sigma_{22}\left\{\begin{array}{r}
<0 \text { if } \lambda_{a}=0 \\
=\lambda_{a} g_{a}=0 \text { if } \lambda_{a}>0
\end{array} .\right.
\end{aligned}
$$

The matrix tensile failure criterion $F^{Y t}$ is commonly evaluated when $\sigma_{22}>0$. The condition of interest from (12) is therefore $\lambda_{a}=0$. Nevertheless, when $\sigma_{22}=0$ the criterion can still be evaluated and it is governed by shear $\tau_{12}$, as can be seen from (1). It can be shown that Lagrange multipliers $\lambda_{a}>0$ may exist in this case. However, this condition will not be further explored here, since the goal is to work on numerical finite element models where it is assumed that $\sigma_{22}=0$ does not happen in practice.
When $\lambda_{a}=0$, the first-order necessary condition in (11), with the aid of (8) and under fixed stress field assumption, is written as:

$$
\begin{aligned}
\left.\frac{\partial L_{Y t}}{\partial \beta}\right|_{\beta^{*}}= & \left(\frac{1}{S_{12}^{2}}-\frac{1}{Y_{t}^{2}}\right) \cos 2 \beta \sin 2 \beta\left(\sigma_{1 p}-\sigma_{2 p}\right)^{2} \\
& +\frac{1}{Y_{t}^{2}} \sin 2 \beta\left(\sigma_{1 p}^{2}-\sigma_{2 p}^{2}\right)=0 .
\end{aligned}
$$

Following (13), the second-order sufficient condition for $\beta$ to be a minimum $\beta^{*}$, when $\lambda_{a}=0$, is given by:

$$
\begin{aligned}
\left.\frac{\partial^{2} L_{Y t}}{\partial \beta^{2}}\right|_{\beta^{*}}= & \left(\frac{2}{S_{12}^{2}}-\frac{2}{Y_{t}^{2}}\right) \cos 4 \beta\left(\sigma_{1 p}-\sigma_{2 p}\right)^{2} \\
& +\frac{2}{Y_{t}^{2}} \cos 2 \beta\left(\sigma_{1 p}^{2}-\sigma_{2 p}^{2}\right)>0 .
\end{aligned}
$$

\subsubsection{Optimal solutions}

Equations 15 and 16 show roots for the stationary condition of (13):

$\beta_{Y t 1}^{*}=0, \quad \beta_{Y t 2}^{*}=\frac{\pi}{2}$,

$\beta_{Y t 3}^{*}=\frac{1}{2} \arccos \left(Q_{Y t}\right), \quad \beta_{Y t 4}^{*}=-\beta_{Y t 3}^{*}$,

where $Q_{Y t}=\frac{S_{12}^{2}\left(\sigma_{1 p}+\sigma_{2 p}\right)}{\left(S_{12}^{2}-Y_{t}^{2}\right)\left(\sigma_{1 p}-\sigma_{2 p}\right)}$.

Equation 13 has other solutions, however, they are obtained by adding multiples of $\pi$ to (15) and (16), and this does not bring any new results regarding material orientation. The solutions to (16) are valid design orientations when $\left(S_{12}^{2}-Y_{t}^{2}\right)\left(\sigma_{1 p}-\sigma_{2 p}\right) \neq 0$ and:

$-1<Q_{Y t}<1$.

The conditions in (18) above guarantee $\beta_{Y t 3}^{*}$ and $\beta_{Y t 4}^{*}$ in (16) to be real, non-complex. When $Q_{Y t}<1$, in view of (17):

$\frac{\sigma_{1 p}-\sigma_{2 p}}{\sigma_{2 p}}+\frac{2 S_{12}^{2}}{Y_{t}^{2}}<0$.

Similarly, $Q_{Y t}>-1$ renders:

$\frac{\sigma_{1 p}-\sigma_{2 p}}{\sigma_{1 p}}-\frac{2 S_{12}^{2}}{Y_{t}^{2}}>0$.

An interesting fact is that multiplying inequalities in (19) and (20), and assuming $S_{12}>Y_{t}$, renders the sufficient condition for $\beta_{Y t 3}^{*}$ and $\beta_{Y t 4}^{*}$ to be minimum points, in terms of (14). Moreover, based on (14), it can be shown that (19) and (20) are, respectively, the sufficient conditions to assure $\beta_{Y t 1}^{*}=0$ and $\beta_{Y t 2}^{*}=\pi / 2$ as maximum points (please see Appendix A for a summary of these solutions).

Therefore, if conditions of (18) are respected, $\beta_{Y t 3}^{*}$ and $\beta_{Y t 4}^{*}$ are the real orientations which minimise Hashin's matrix tensile criterion. When (18) has a condition not 
respected, the inequalities in (19) and (20) change, and either $\beta_{Y t 1}^{*}=0$ or $\beta_{Y t 2}^{*}=\pi / 2$ has sufficient conditions to satisfy a minimum point. Thus, a minimum solution is always possible. Finally, it is clear that the solutions $\beta_{Y t}^{*}$ and their optimality depend on principal stresses and material strength parameters.

\subsection{Matrix compressive failure criterion}

\subsubsection{Derivation of optimality conditions}

Rewriting (2) in terms of principal stresses $\left|\sigma_{1 p}\right|>\left|\sigma_{2 p}\right|$ and orientation $\beta$, using (6) and (7), renders:

$$
\begin{aligned}
F^{Y c}(\beta)= & \frac{1}{16 S_{23}^{2}}\left[\sigma_{1 p}+\sigma_{2 p}-\cos 2 \beta\left(\sigma_{1 p}-\sigma_{2 p}\right)\right]^{2} \\
& +\frac{1}{4 S_{12}^{2}} \sin ^{2} 2 \beta\left(\sigma_{1 p}-\sigma_{2 p}\right)^{2} \\
& +\frac{C_{Y c}}{2 Y_{c}}\left[\sigma_{1 p}+\sigma_{2 p}-\cos 2 \beta\left(\sigma_{1 p}-\sigma_{2 p}\right)\right] .
\end{aligned}
$$

In (21), $C_{Y c}$ is a material constant given by:

$C_{Y c}=\left(\frac{Y_{c}}{2 S_{23}}\right)^{2}-1$.

The failure mode in (21) is evaluated when $\sigma_{22}<0$. In order to minimise this criterion, the following standard optimisation problem is stated:

$$
\underset{\beta}{\operatorname{minimise}} \quad F^{Y c}(\beta)
$$

subject to: $\quad g_{b}=\sigma_{22}(\beta) \leq 0$.

In this problem, $F^{Y c}$ is the objective function to be minimised in $\beta$ and $g_{b} \leq 0$ is a standard inequality constraint. Defining the Lagrange multiplier $\lambda_{b}$, the Lagrangian function $L_{Y c}$ for the problem in (23) is:

$L_{Y c}\left(\beta, \lambda_{b}\right)=F^{Y c}(\beta)+\lambda_{b} \sigma_{22}(\beta)$.

The first-order necessary conditions for $L_{Y c}\left(\beta, \lambda_{b}\right)$ at stationary points (where $\beta=\beta^{*}$ ) are:

$$
\begin{aligned}
& \left.\frac{\partial L_{Y c}}{\partial \beta}\right|_{\beta^{*}}=\frac{\partial F^{Y c}}{\partial \beta}+\lambda_{b} \frac{\partial \sigma_{22}}{\partial \beta}=0, \\
& \left.\frac{\partial L_{Y c}}{\partial \lambda_{b}}\right|_{\beta^{*}}=\sigma_{22}\left\{\begin{array}{r}
<0 \text { if } \lambda_{b}=0 \\
=\lambda_{b} g_{b}=0 \text { if } \lambda_{b}>0
\end{array} .\right.
\end{aligned}
$$

The matrix compressive criterion $F^{Y c}$ is evaluated when $\sigma_{22}<0$. Following the same assumption as for the matrix tensile criterion, the condition $\sigma_{22}=0$ is not taken into account here. Therefore, the condition of interest from (26) is $\lambda_{b}=0$. In view of this result, the first-order necessary condition in (25), also in view of (21) and under fixed stress field assumption, is determined as:

$$
\begin{aligned}
\left.\frac{\partial L_{Y c}}{\partial \beta}\right|_{\beta^{*}}= & \left(\frac{1}{S_{12}^{2}}-\frac{1}{4 S_{23}^{2}}\right) \cos 2 \beta \sin 2 \beta\left(\sigma_{1 p}-\sigma_{2 p}\right)^{2} \\
& +\frac{1}{4 S_{23}^{2}} \sin 2 \beta\left(\sigma_{1 p}^{2}-\sigma_{2 p}^{2}\right) \\
& +\frac{C_{Y c}}{Y_{c}} \sin 2 \beta\left(\sigma_{1 p}-\sigma_{2 p}\right)=0 .
\end{aligned}
$$

Moreover, when $\lambda_{b}=0$, the respective second-order sufficient condition for $\beta$ to be a minimum $\left(\beta^{*}\right)$, following (27), is:

$$
\begin{aligned}
\left.\frac{\partial^{2} L_{Y c}}{\partial \beta^{2}}\right|_{\beta^{*}}= & \left(\frac{2}{S_{12}^{2}}-\frac{1}{2 S_{23}^{2}}\right) \cos 4 \beta\left(\sigma_{1 p}-\sigma_{2 p}\right)^{2} \\
& +\frac{1}{2 S_{23}^{2}} \cos 2 \beta\left(\sigma_{1 p}^{2}-\sigma_{2 p}^{2}\right) \\
& +\frac{2 C_{Y c}}{Y_{c}} \cos 2 \beta\left(\sigma_{1 p}-\sigma_{2 p}\right)>0 .
\end{aligned}
$$

\subsubsection{Optimal solutions}

The following equations show roots for the stationary condition in (27):

$\beta_{Y c 1}^{*}=0, \quad \beta_{Y c 2}^{*}=\frac{\pi}{2}$,

$\beta_{Y c 3}^{*}=\frac{1}{2} \arccos \left(Q_{Y c}\right), \quad \beta_{Y c 4}^{*}=-\beta_{Y c 3}^{*}$,

where $Q_{Y c}=\frac{S_{12}^{2}\left[4 C_{Y c} S_{23}^{2}+Y_{c}\left(\sigma_{1 p}+\sigma_{2 p}\right)\right]}{Y_{c}\left(S_{12}^{2}-4 S_{23}^{2}\right)\left(\sigma_{1 p}-\sigma_{2 p}\right)}$.

Equation 27 has other solutions, obtained by adding multiples of $\pi$ to (29) and (30). However, this does not bring any new results in terms of material orientation. The solutions of (30) are valid design orientations when $Y_{c}\left(S_{12}^{2}-\right.$ $\left.4 S_{23}^{2}\right)\left(\sigma_{1 p}-\sigma_{2 p}\right) \neq 0$ and:

$-1<Q_{Y c}<1$.

The conditions in (32) must hold when $\beta_{Y_{c 3}}^{*}$ and $\beta_{Y c 4}^{*}$ in (30) are real numbers. When $Q_{Y c}<1$ in view of (31), it implies:

$\frac{\left(\sigma_{1 p}-\sigma_{2 p}\right)}{\sigma_{2 p}}+\frac{S_{12}^{2} C_{Y c}}{Y_{c} \sigma_{2 p}}+\frac{S_{12}^{2}}{2 S_{23}^{2}}<0$.

The condition $Q_{Y c}>-1$ implies:

$-\frac{\left(\sigma_{1 p}-\sigma_{2 p}\right)}{\sigma_{1 p}}+\frac{S_{12}^{2} C_{Y c}}{Y_{c} \sigma_{1 p}}+\frac{S_{12}^{2}}{2 S_{23}^{2}}>0$.

Interestingly, multiplying (33) by (34) renders an inequality which is the sufficient second-order condition for both $\beta_{Y c 3}^{*}$ and $\beta_{Y c 4}^{*}$ to be minimum points, in view of (28). Moreover, also based on (28), it can be shown that (33) and 
(34) are, respectively, the sufficient conditions that ensure $\beta_{Y c 1}^{*}=0$ and $\beta_{Y c 2}^{*}=\pi / 2$ as maximum points (Appendix A provides a summary of these solutions).

Therefore, if conditions of (32) are obeyed, $\beta_{Y c 3}^{*}$ and $\beta_{Y c 4}^{*}$ are the real orientations that minimise Hashin's matrix compressive criterion. When (32) has a condition not respected, the inequalities in (33) and (34) change, and either $\beta_{Y c 1}^{*}=0$ or $\beta_{Y c 2}^{*}=\pi / 2$ has the sufficient condition to be a minimum point respected. Thus, a minimum solution is always possible.

It can be seen that solutions for $\beta_{Y c}^{*}$ and their optimality depend on the principal stresses and material strength parameters. Moreover, in view of the load-response linearity from linear elasticity, optimal solutions also depend on the magnitude of external loads for this particular criterion. This is noticed once load magnitude effects are not cancelled in optimality results in (27)-(34).

\subsection{Fibre tensile failure criterion}

\subsubsection{Derivation of optimality conditions}

It is possible to rewrite (3) in terms of principal stresses $\left|\sigma_{1 p}\right|>\left|\sigma_{2 p}\right|$ and orientation $\beta$, with the aid of (5) and (7), as:

$$
\begin{aligned}
F^{X t}(\beta)= & \frac{1}{4 X_{t}^{2}}\left[\sigma_{1 p}+\sigma_{2 p}+\cos 2 \beta\left(\sigma_{1 p}-\sigma_{2 p}\right)\right]^{2} \\
& +\frac{1}{4 S_{12}^{2}}\left[\sin 2 \beta\left(\sigma_{1 p}-\sigma_{2 p}\right)\right]^{2} .
\end{aligned}
$$

Since this failure mode is evaluated when $\sigma_{11}>0$, the following optimisation problem is stated in standard form:

$\underset{\beta}{\operatorname{minimise}} \quad F^{X t}(\beta)$

subject to: $g_{c}=-\sigma_{11}(\beta) \leq 0$.

In this problem, $F^{X t}$ is the objective function to be minimised in $\beta$ and $g_{c} \leq 0$ is a standard inequality constraint. Considering the Lagrange multiplier $\lambda_{c}$, the Lagrangian function $L_{X t}$ for the problem in (36) is written as:

$L_{X t}\left(\beta, \lambda_{c}\right)=F^{X t}(\beta)-\lambda_{c} \sigma_{11}(\beta)$.

First-order necessary conditions for $L_{X t}\left(\beta, \lambda_{c}\right)$ at stationary points (where $\beta=\beta^{*}$ ) are:

$\left.\frac{\partial L_{X t}}{\partial \beta}\right|_{\beta^{*}}=\frac{\partial F^{X t}}{\partial \beta}-\lambda_{c} \frac{\partial \sigma_{11}}{\partial \beta}=0$,

$\left.\frac{\partial L_{X t}}{\partial \lambda_{c}}\right|_{\beta^{*}}=-\sigma_{11}\left\{\begin{array}{r}<0 \text { if } \lambda_{c}=0 \\ =\lambda_{c} g_{c}=0 \text { if } \lambda_{c}>0\end{array}\right.$.

The fibre tensile failure criterion $F^{X t}$ is only evaluated when $\sigma_{11}>0$. Moreover, in view of the present interest in finite element numerical analyses, it is assumed that $\sigma_{11}=$
0 does not happen in practice. Therefore, the solution of interest from the conditions in (39) is $\lambda_{c}=0$. In view of this result and (35), the first-order necessary condition in (38), under fixed stress field assumption, is written as:

$$
\begin{aligned}
\left.\frac{\partial L_{X t}}{\partial \beta}\right|_{\beta^{*}}= & \left(\frac{1}{S_{12}^{2}}-\frac{1}{X_{t}^{2}}\right) \cos 2 \beta \sin 2 \beta\left(\sigma_{1 p}-\sigma_{2 p}\right)^{2} \\
& -\frac{1}{X_{t}^{2}} \sin 2 \beta\left(\sigma_{1 p}^{2}-\sigma_{2 p}^{2}\right)=0 .
\end{aligned}
$$

Following (40), when $\lambda_{c}=0$, the corresponding secondorder sufficient condition for $\beta$ to be a minimum $\left(\beta^{*}\right)$ of $F^{X t}$ is given by:

$$
\begin{aligned}
\left.\frac{\partial^{2} L_{X t}}{\partial \beta^{2}}\right|_{\beta^{*}}= & \left(\frac{2}{S_{12}^{2}}-\frac{2}{X_{t}^{2}}\right) \cos 4 \beta\left(\sigma_{1 p}-\sigma_{2 p}\right)^{2} \\
& -\frac{2}{X_{t}^{2}} \cos 2 \beta\left(\sigma_{1 p}^{2}-\sigma_{2 p}^{2}\right)>0 .
\end{aligned}
$$

\subsubsection{Optimal solutions}

It is easily seen that $\beta_{X t 1}^{*}=0$ is a solution of (40). This equation has other roots, as shown in Appendix A. For $\beta_{X t 1}^{*}=0$, the sufficient minimisation condition of (41) becomes:

$\left.\frac{\partial^{2} L_{X t}}{\partial \beta^{2}}\right|_{\beta_{X t 1}^{*}}=\frac{\sigma_{1 p}-\sigma_{2 p}}{\sigma_{1 p}}-\frac{2 S_{12}^{2}}{X_{t}^{2}}>0$.

It is noticeable that the optimality of the solution $\beta_{X t 1}^{*}=$ 0 depends on the principal stresses and material strength parameters. However, if $X_{t}>>S_{12}$ (for fibre composites, $X_{t}>S_{12}$ is usual), the fraction involving $S_{12}$ and $X_{t}$ in (42) tends to be a small number. In that particular case, and defining $0^{+}$as a small positive number, (42) renders:

$\left.\frac{\partial^{2} L_{X t}}{\partial \beta^{2}}\right|_{\beta_{X t 1}^{*}}=\frac{\sigma_{1 p}-\sigma_{2 p}}{\sigma_{1 p}}>0^{+}$.

The condition in (43) will be met if $\sigma_{2 p}$ does not approach $\sigma_{1 p}$. In this case, since $\left|\sigma_{1 p}\right|>\left|\sigma_{2 p}\right|, \beta_{X t 1}^{*}=0$ is a minimum point.

\subsection{Fibre compressive failure criterion}

\subsubsection{Derivation of optimality conditions}

Equation 4 can be rewritten in terms of principal stresses $\left|\sigma_{1 p}\right|>\left|\sigma_{2 p}\right|$ and orientation $\beta$ using (5):

$F^{X c}(\beta)=\frac{1}{-2 X_{c}}\left[\left(\sigma_{1 p}+\sigma_{2 p}\right)+\left(\sigma_{1 p}-\sigma_{2 p}\right) \cos 2 \beta\right]$. 
The criterion in (44) is evaluated if $\sigma_{11}<0$. Thus, the following optimisation problem is stated, in standard form:

$$
\begin{array}{ll}
\underset{\beta}{\operatorname{minimise}} & F^{X c}(\beta) \\
\text { subject to: } & g_{d}=\sigma_{11}(\beta) \leq 0 .
\end{array}
$$

In the problem above, $F^{X c}$ is the objective function under minimisation in $\beta$ and $g_{d} \leq 0$ is an inequality constraint in standard form. Considering the Lagrange multiplier $\lambda_{d}$, the Lagrangian function $L_{X c}$ for the problem in (45) is written as:

$L_{X c}\left(\beta, \lambda_{d}\right)=F^{X c}(\beta)+\lambda_{d} \sigma_{11}(\beta)$.

The first-order necessary conditions for $L_{X c}\left(\beta, \lambda_{d}\right)$ at stationary points (where $\beta=\beta^{*}$ ) are:

$\left.\frac{\partial L_{X c}}{\partial \beta}\right|_{\beta^{*}}=\frac{\partial F^{X c}}{\partial \beta}+\lambda_{d} \frac{\partial \sigma_{11}}{\partial \beta}=0$,

$\left.\frac{\partial L_{X c}}{\partial \lambda_{d}}\right|_{\beta^{*}}=\sigma_{11}\left\{\begin{array}{r}<0 \text { if } \lambda_{d}=0 \\ =\lambda_{d} g_{d}=0 \text { if } \lambda_{d}>0\end{array}\right.$.

The fibre compressive failure criterion $F^{X c}$ is evaluated when $\sigma_{11}<0$. Following the same assumption as for the fibre tensile criterion, the condition $\sigma_{11}=0$ is not taken into account here. Therefore, the condition of interest from (48) is $\lambda_{d}=0$. In view of this result and (44), noticing that $X_{c}$ is a constant and under fixed stress field assumption, the first-order necessary condition in (47) is written as:

$\left.\frac{\partial L_{X c}}{\partial \beta}\right|_{\beta^{*}}=\sin 2 \beta\left(\sigma_{1 p}-\sigma_{2 p}\right)=0$.

For (49), the corresponding second-order sufficient condition, to qualify a stationary point $\beta$ as minimum $\left(\beta^{*}\right)$, is:

$\left.\frac{\partial^{2} L_{X c}}{\partial \beta^{2}}\right|_{\beta^{*}}=2 \cos 2 \beta\left(\sigma_{1 p}-\sigma_{2 p}\right)>0$.

\subsubsection{Optimal solutions}

The optimality conditions for this criterion, (49) and (50), depend on the principal stresses and not on any material properties. A solution is $\beta_{X c 1}^{*}=0$ which, with principal stresses $\left|\sigma_{1 p}\right|>\left|\sigma_{2 p}\right|$, is a maximum point if $\sigma_{1 p}<0$. A summary of solutions is shown in Appendix A.

\subsection{A note on sensitivities of the failure criteria}

The sensitivities in the OC of Hashin's failure criteria in Sections 3.1, 3.2, 3.3 and 3.4 were evaluated based on a fixed stress field assumption. This implies that a change in the local material orientation of a design region does not significantly affect the stress field of the full structure, i.e. mutual sensitivities of $\beta$ are not considered.
In fact, the Lagrangian functions dealt with in (10), (24), (37) and (46) depend on all local material orientations $\beta$ that the structure may have, and can be written in the following general form:

$L\left(\sigma_{1 p}(\mathbf{b}), \sigma_{2 p}(\mathbf{b}), f_{1}(\beta), f_{2}(\beta), \lambda\right)$.

In (51), $\sigma_{1 p}$ and $\sigma_{2 p}$ are functions of the vector $\mathbf{b}^{T}=\left\{\beta_{1}, \ldots, \beta, \ldots, \beta_{N}\right\}$, which collects all local material orientations $\beta$ of all possible design regions (assumed small) in a structure. The Lagrangian function general form in (51) also depends on the respective Lagrange multiplier $\lambda$, as well on functions $f_{1}(\beta)=\sin 2 \beta$ and $f_{2}(\beta)=\cos 2 \beta$, which vary only with the single $\beta$ in question in Section 3.1 to 3.4. Considering the generalised chain rule of partial derivatives, the first derivative in $\beta$ of (51) renders (with $\lambda$ assumed as a constant):

$\frac{\partial L}{\partial \beta}=\frac{\partial L}{\partial \sigma_{1 p}} \frac{\partial \sigma_{1 p}}{\partial \beta}+\frac{\partial L}{\partial \sigma_{2 p}} \frac{\partial \sigma_{2 p}}{\partial \beta}+\frac{\partial L}{\partial f_{1}} \frac{d f_{1}}{d \beta}+\frac{\partial L}{\partial f_{2}} \frac{d f_{2}}{d \beta}$.

Under fixed stress field assumption, it is considered that $\frac{\partial \sigma_{1 p}}{\partial \beta}=\frac{\partial \sigma_{2 p}}{\partial \beta}=0$ in (52). Furthermore, it is implicit that the derivatives of Lagrangian functions with respect to all other variables in $\mathbf{b}$, except $\beta$, are not important in the $\mathrm{OC}$ derived. In other words, it is neglected the mutual influence of $\mathbf{b}$ on the stress field and derived OC. This is a simplifying assumption that permits the $\mathrm{OC}$ to be solved analytically as presented, since in this case only the terms involving $f_{1}$ and $f_{2}$ are taken into account in the derivatives of respective $L$ in Sections 3.1 to 3.4 (e.g. (13) and (14)). However, it is here expected that the method will iteratively converge to a design point in which the fixed stress field assumption has little effect on the final obtained result.

\section{Optimisation strategy}

Based on the OC derived in Section 3, the HA-OCM was developed to tackle the problem of finding, in structures represented by finite element (FE) meshes, element-wise material orientations for strength improvement. In summary, it is a simple strategy based on calculating element-wise orientations $\beta^{*}$ that minimise the Hashin criteria associated with matrix failure (either tensile or compressive), and then iteratively changing local material orientations in order to achieve optimal design solutions. The orientation choice can be focused on satisfying the matrix criteria because the strengths in the matrix direction (either tensile $Y_{t}$ or compressive $Y_{c}$, in direction 2) are much lower than the strengths in the fibre direction for unidirectional fibre-reinforced composites. The material properties given in Table 1 exemplify this aspect. Therefore, the optimal finite element-wise orientations are designed to locally minimise the matrix failure criteria. 


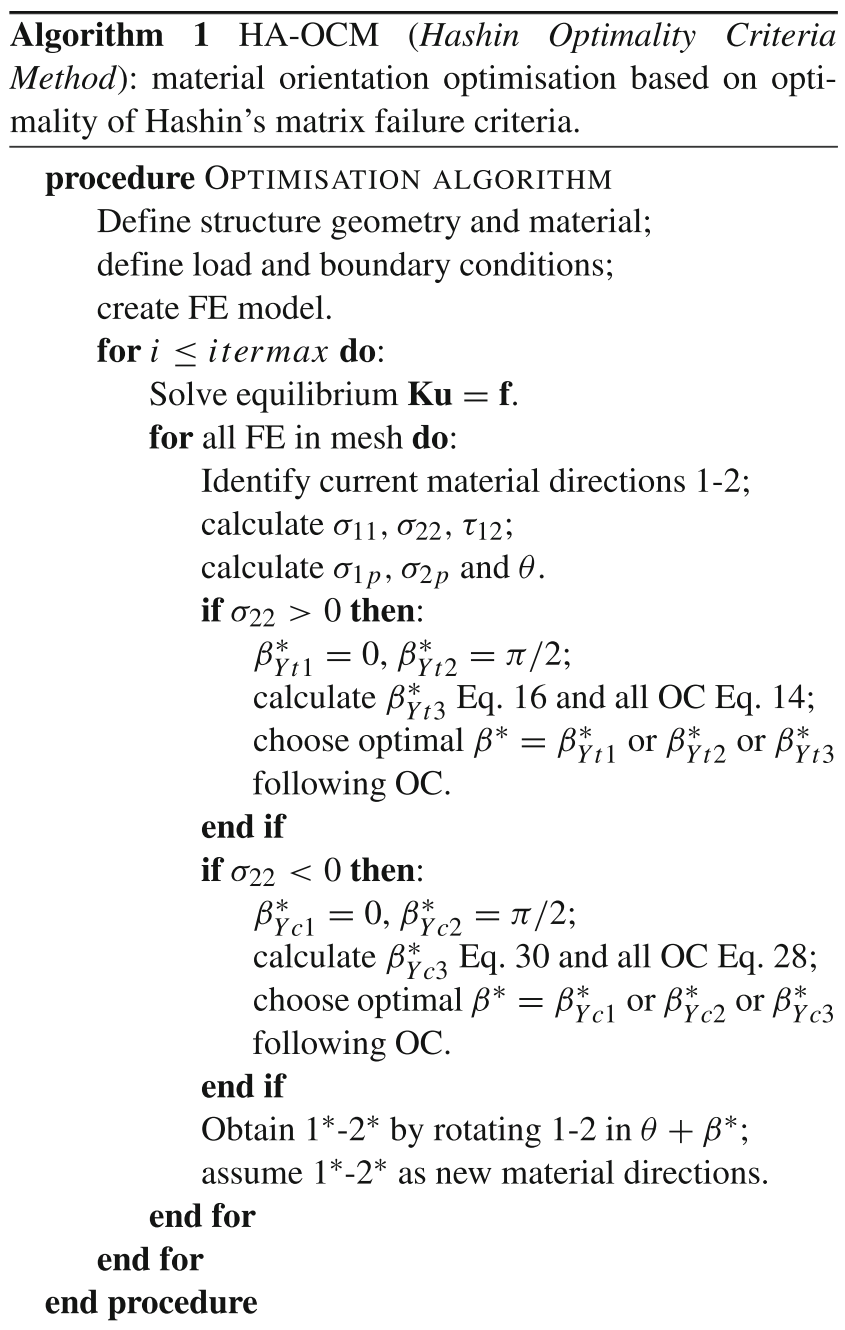

Algorithm 1 shows a pseudo-code for the HA-OCM, implemented using the commercial FE software ABAQUS and Python coding. Basically, it determines orientation solutions among $0, \pi / 2$ and $\beta_{Y t 3}^{*}$ or $\beta_{Y c 3}^{*}$ which minimises the active matrix failure criterion. Solutions $\beta_{Y t 4}^{*} / \beta_{Y c 4}^{*}$ are not considered, in order to eliminate the need for choice between them and $\beta_{Y t 3}^{*} / \beta_{Y c 3}^{*}$. This was based on early-stage tests that showed they were not strictly necessary in order to improve failure loads, and removing them increases the efficiency of the algorithm.

Figure 1 shows definitions of the axis systems and angular rotations in the HA-OCM. The rotation $\alpha$ is defined from the global $X$ axis of the structure to the current local material 1 axis. After calculating stresses in the 1-2 system, the rotation $\theta$ from direction 1 to principal stress $\sigma_{1 p}$ direction is found using the standard (Kelly 2015) plane stress formula:

$\tan 2 \theta=\frac{2 \tau_{12}}{\sigma_{11}-\sigma_{22}}$.

Finally, the optimal orientation $\beta^{*}$ is defined as the angle between the principal axis $1 p$ and the optimal local

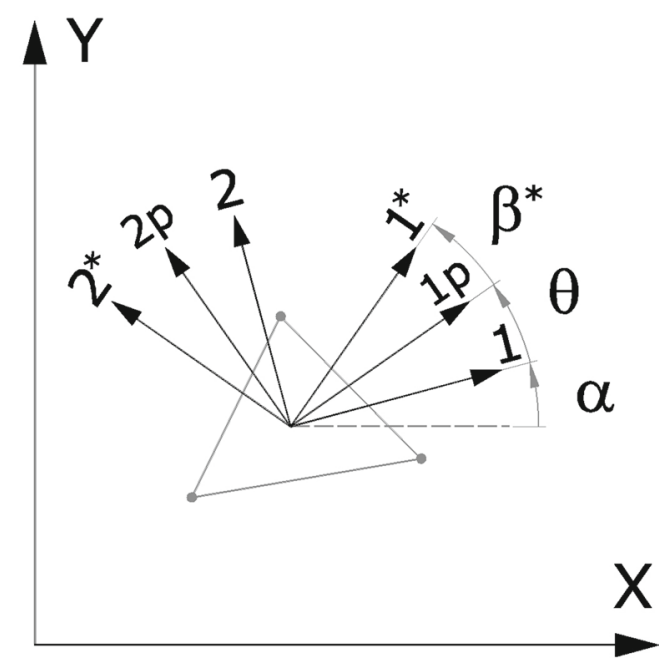

Fig. 1 Definition of angles between axis systems: $\alpha$ from global $X-Y$ to local material 1-2, then $\theta$ from 1-2 to principal $1 p-2 p$, and $\beta^{*}$ from $1 p-2 p$ to optimal $1 *-2 *$

material axis $1^{*}$, as determined by satisfying the optimality conditions for the Hashin matrix failure criteria. In terms of stress, the local material stresses $\left(\sigma_{11}, \sigma_{22}, \tau_{12}\right)$ are used to calculate the principal stresses $\left(\sigma_{1 p}, \sigma_{2 p}\right)$, followed by the optimal local material orientation $\beta^{*}$, from which the stresses in optimal material directions $\left(\sigma_{11}^{*}, \sigma_{22}^{*}, \tau_{12}^{*}\right)$ are determined.

The underpinning hypothesis for the proposed method is that increased failure loads for the structure as a whole can be achieved by sequentially imposing, elementwise, the local material orientation $\beta^{*}$ that minimises the matrix failure criteria. It is expected that designs will reach convergence, justifying the use of the fixed stress field assumption followed in the derivation of the OC in Section 3.

\section{Results}

The proposed optimisation method HA-OCM was applied to three examples of single-layered plane structures: a cantilever plate, a plate with a central hole and a bracketshaped plate under either compressive or tensile loading. The first example was chosen for an initial assessment of the optimisation strategy. The two subsequent examples were used to evaluate the potential of applicability of the present methodology to gradually more complex domains. However, it has to be mentioned that the designs of notched composites (Tan 1994; Trinh 1997) and multi-load structures involve concepts beyond the focus of the present article.

For comparisons with HA-OCM results, a principal stress design strategy was also applied to the same examples, 
based on iteratively aligning, element-wise, the stiffest local material directions (here the 1-directions) with the directions of the maximum principal stresses in absolute (here defined as $\sigma_{1 p}$, once $\left|\sigma_{1 p}\right|>\left|\sigma_{2 p}\right|$ is assumed).

The designs obtained are compared in terms of failure loads, as evaluated according to the Hashin criteria, and compliance. The materials considered in the tests are shown in Table 1 and referred to as follows: 3DCF (3D printed carbon fibre and nylon composite), CF (carbon fibre and epoxy composite) and GF (glass fibre and epoxy composite). For all cases tested, both optimisation strategies were run for a total of 100 iterations (which is the HA-OCM stopping criterion). In all cases shown, the initial designs had all elements' material 1-directions aligned at $0^{\circ}$ to the $X$-axis in Figs. 2, 7 and 10.

\subsection{Problem 1: Cantilever plate structure}

The square plane structure shown in Fig. 2, with a thickness of $0.51 \mathrm{~mm}$, is clamped on the leftmost side and has a constant distributed load applied on the rightmost side, as indicated. It was discretised in ABAQUS using $98 \mathrm{~S} 3 \mathrm{R}$ general shell elements, and was optimised for the 3DCF, $\mathrm{CF}$ and GF materials. Figure 3 shows the final designs in terms of material orientations (plotted alongside maximum principal stresses in absolute $\sigma_{1 p}$ ), Fig. 4 shows results obtained throughout iterations and convergence for failure load and compliance for each design and Table 2 shows a summary of the final results. The designs $(a)$ to $(c)$ were obtained using the HA-OCM and $(d)$ to $(f)$ by principal stress design.

The loads used in the optimisation were $F=20 \mathrm{~N} / \mathrm{mm}^{2}$ for $3 \mathrm{DCF}$ cases $(a)$ and $(d), F=30 \mathrm{~N} / \mathrm{mm}^{2}$ for $\mathrm{CF}$ cases $(b)$ and $(e)$, and $F=10 \mathrm{~N} / \mathrm{mm}^{2}$ for GF cases $(c)$ and $(f)$. These magnitudes were chosen after initial tests, and were proven to deliver final designs without failure according to

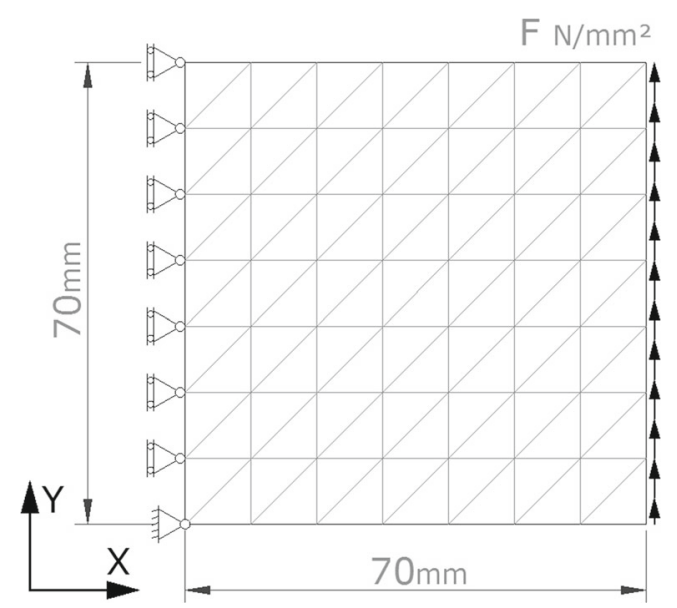

Fig. 2 Problem 1 - structure, load and boundary conditions
Proposed Hashin Design

(a) 3DCF

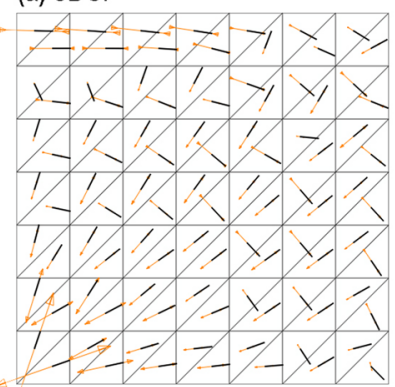

(b) $\mathrm{CF}$

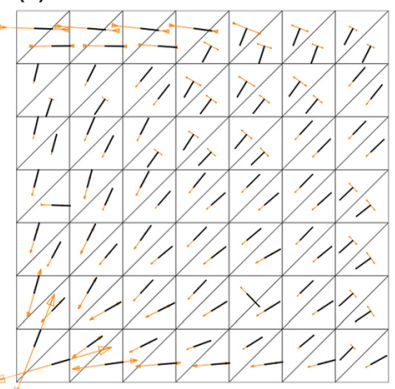

(c) GF

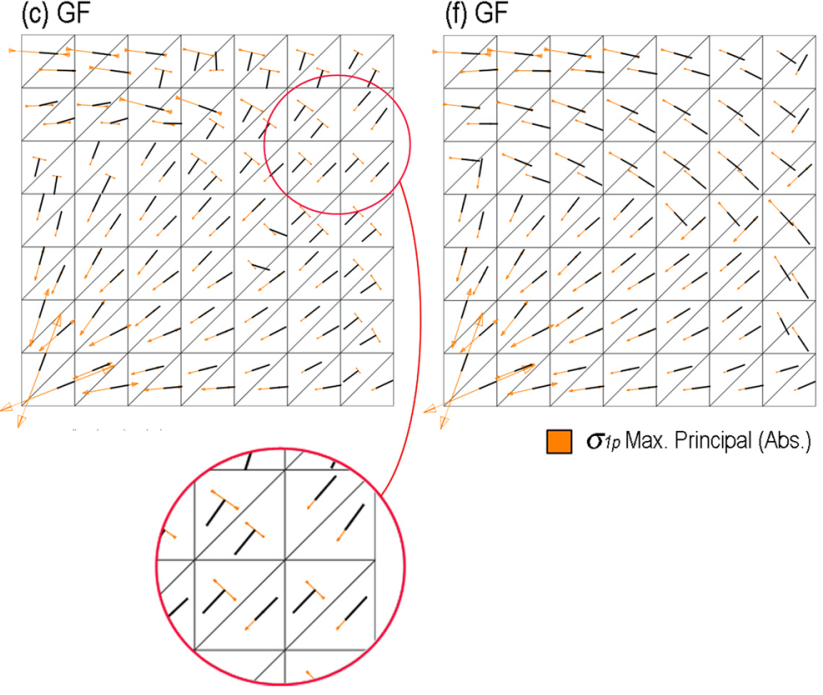

Fig. 3 Problem 1: final designs obtained by the here proposed HAOCM, $(a)$ to $(c)$, and principal stress design, $(d)$ to $(f)$. Orange arrows are maximum principal stresses in absolute $\sigma_{1 p}$. Black lines are local material 1-directions (fibre). In $(g)$, the red circle highlights the occurrence of material oriented at $0^{\circ}$ and $90^{\circ}$ with the principal stress direction at the optimised design, a possible result in HA-OCM

any of the Hashin's criteria, for the HA-OCM. Principal stress design is independent of load magnitude.

From the results presented in Table 2, it is noticeable that the HA-OCM was able to obtain designs with higher failure loads than the principal stress design. For cases $(a)$ and (b), the obtained failure loads were increased by $71 \%$ and $77 \%$, respectively, in comparison with the principal stress designs $(d)$ and $(e)$. For the $(c)$ case, however, the gain was only $2.7 \%$ in comparison with the respective case $(f)$. 

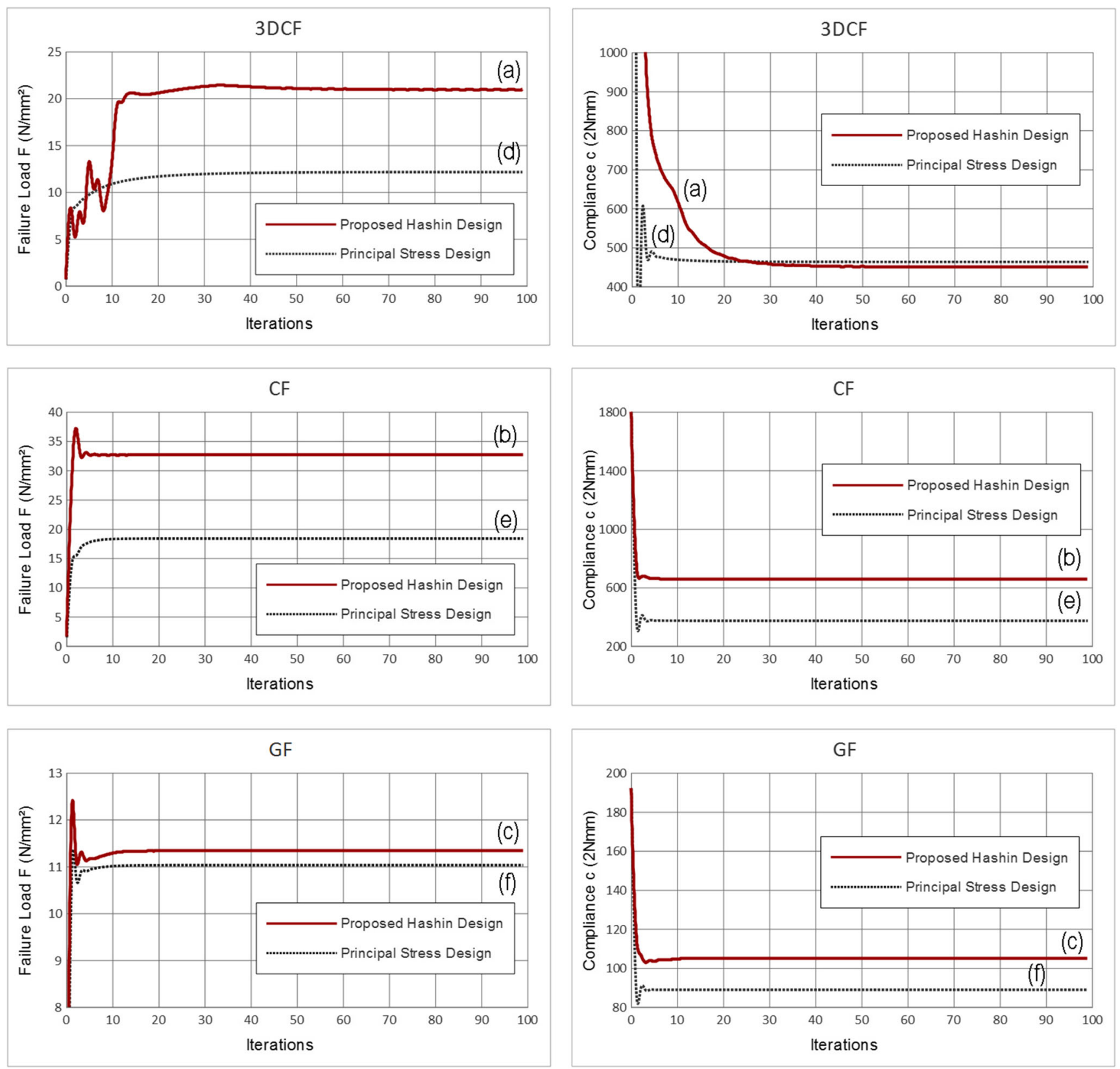

Fig. 4 Problem 1: failure loads and compliance throughout iterations, for cases $(a)$ to $(f)$

It is also notable that the two design strategies provided different designs in terms of the element fibre orientations, as seen in Fig. 3. This is discussed in detail in the next section.

\subsubsection{Compliance optimality analysis}

From Fig. 3, it is seen that the HA-OCM results $(a)$ to (c) mainly have the material 1-directions (stiffest) either
Table 2 Problem 1: failure loads and compliance for designs $(a)$ to $(f)$ in Fig. 3, at final 100th iteration
Proposed Failure load Failure Compliance Principal Failure load Failure Compliance HA-OCM $F^{*}\left(\mathrm{~N} / \mathrm{mm}^{2}\right)$ mode $c^{*}(2 \mathrm{Nmm})$ stress Des. $F^{*}\left(\mathrm{~N} / \mathrm{mm}^{2}\right)$ mode $c^{*}(2 \mathrm{Nmm})$

\begin{tabular}{llllllll}
\hline (a) & 20.933 & FT & 449.767 & (d) & 12.177 & MC & 464.024 \\
(b) & 32.630 & MC & 658.430 & (e) & 18.420 & MC & 375.324 \\
(c) & 11.334 & MT & 105.017 & (f) & 11.036 & MT & 89.020 \\
\hline
\end{tabular}


Table 3 Problem 1: post-

analysis of obtained results $(a)$ to $(f)$, using Pedersen's OC for compliance in terms of material orientation (Pedersen 1989,

1990) (here in Appendix A),

evaluated at each of the $98 \mathrm{FE}$

of the cantilever plate mesh

\begin{tabular}{|c|c|c|c|c|c|c|c|}
\hline \multirow{2}{*}{$\begin{array}{l}\text { Proposed } \\
\text { HA-OCM }\end{array}$} & \multicolumn{3}{|c|}{ For compliance, number of FE at: } & \multirow{2}{*}{$\begin{array}{l}\text { Principal } \\
\text { stress Des. }\end{array}$} & \multicolumn{3}{|c|}{ For compliance, number of $\mathrm{FE}$ at: } \\
\hline & Global min. & Local min. & Not min. & & Global min. & Local min. & Not min. \\
\hline (a) & 58 & 35 & 5 & (d) & 34 & 64 & - \\
\hline (b) & 21 & 74 & 3 & (e) & 33 & 65 & - \\
\hline (c) & 31 & 60 & 7 & (f) & 55 & 43 & - \\
\hline
\end{tabular}

aligned with the directions of maximum absolute principal stress or at $90^{\circ}$ to them (the latter is a perfectly possible optimal result for strength according to the OC here presented; see e.g. Appendix A). Whereas, as expected, the principal stress designs have all material 1-directions aligned with directions of maximum absolute principal stress. These material orientations represent point-wise conditions for extreme compliance, based on the OC presented by Pedersen in Pedersen (1989, 1990): here summarised in Appendix B.
Failure Indices

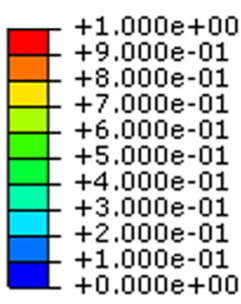

\section{Matrix Tensile Mode}

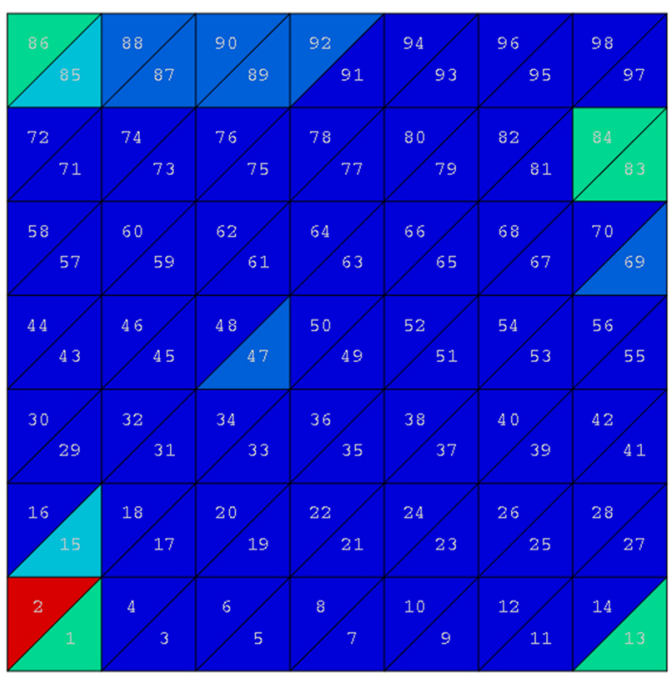

\section{Fibre Tensile Mode}

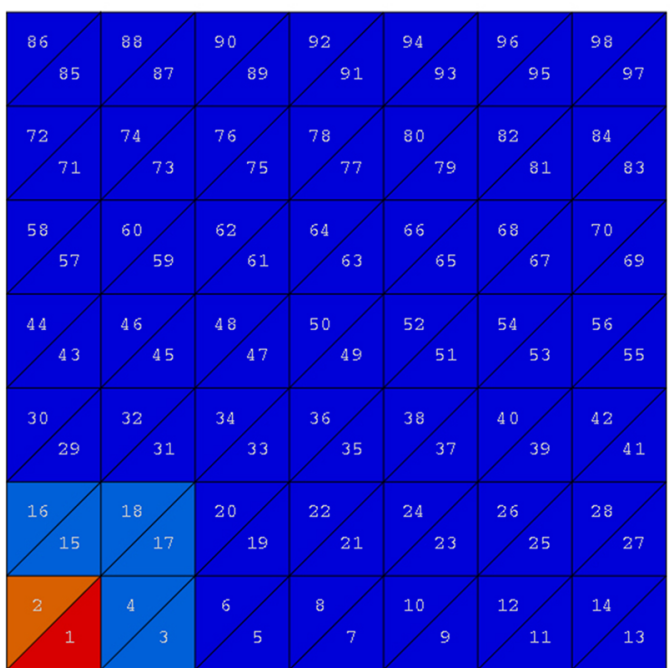

\section{Matrix Compressive Mode}

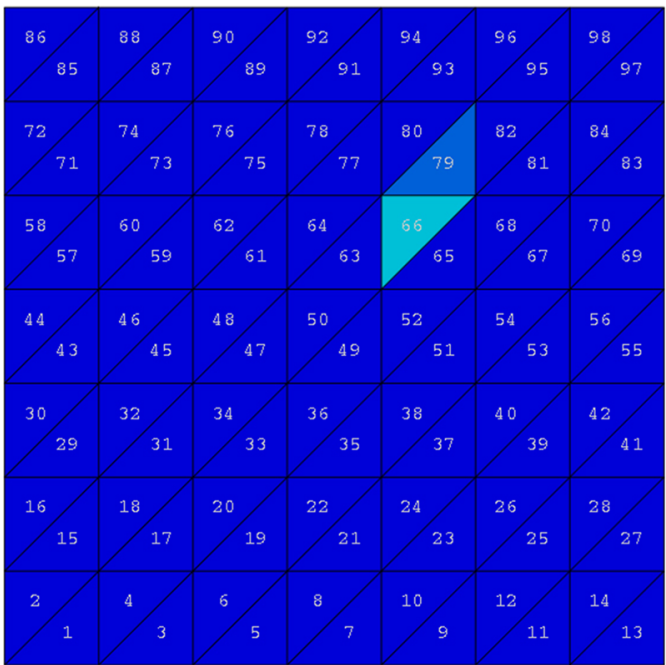

Fibre Compressive Mode

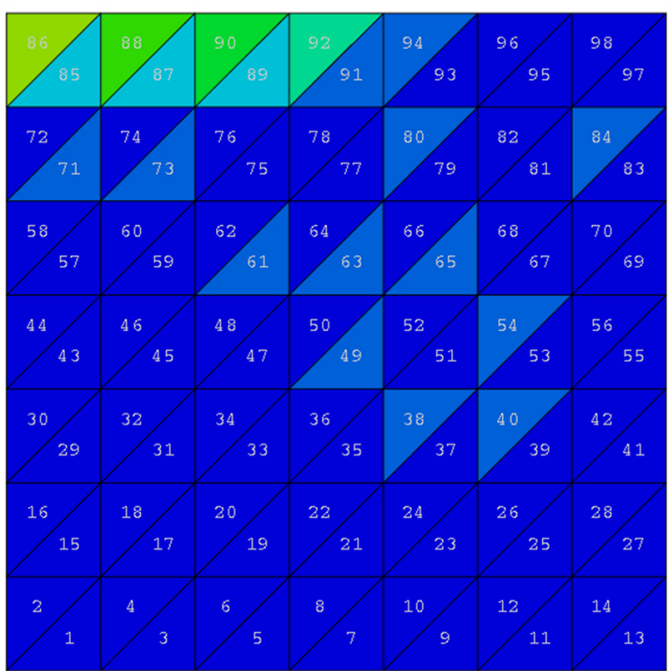

Fig. 5 Problem 1: element-wise indices of Hashin's failure criteria for HA-OCM result in Fig. 3a. Load $F=20 \mathrm{~N} / \mathrm{mm}^{2}$ 
Evaluating the compliances of the final designs (low compliance meaning high stiffness), it can be seen in Fig. 4 that both design strategies were able to reduce compliances from the initial designs. However, the HA-OCM delivered higher final compliances compared with the principal stress design in cases $(b)$ and $(c)$, with compliance greater by $75 \%$ and $18 \%$, respectively. In order to explain these data, Pedersen's OC for minimum compliance in Pedersen (1989, 1990) were evaluated for all results here obtained, by post-processing optimised designs in terms of material orientation for all cases $(a)$ to $(f)$. Results from these OC are summarised in Table 3.

From Table 3, it is seen that designs $(b)$ and $(c)$ had more element-wise material orientations set to angles that represent compliance local minimum points, instead of global minimum points, in comparison with their respective pairs $(e)$ and $(f)$ found by principal stress design. Another interesting fact is that in results $(d)$ to $(f)$, obtained by principal stress design, not all local material orientations were set to angles that render global minimum compliance. Therefore, neither the HA-OCM nor principal stress design guaranteed global minimum compliance in view of the OC in Pedersen $(1989,1990)$.

\subsubsection{Details on failure modes}

Figures 5 and 6 show plots of element-wise indices of Hashin's criteria for designs $(a)$ and $(d)$ in Fig. 3,
Failure Indices

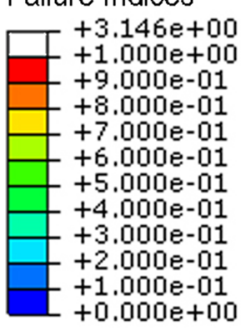

Matrix Tensile Mode

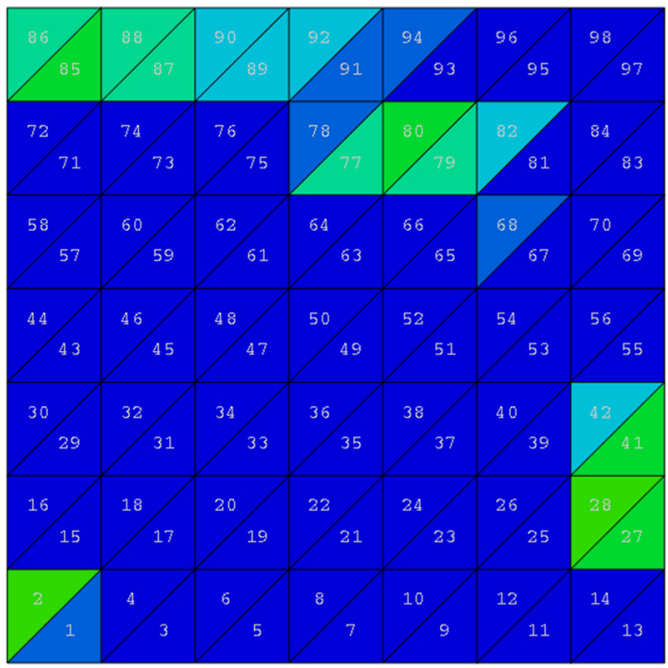

Fibre Tensile Mode

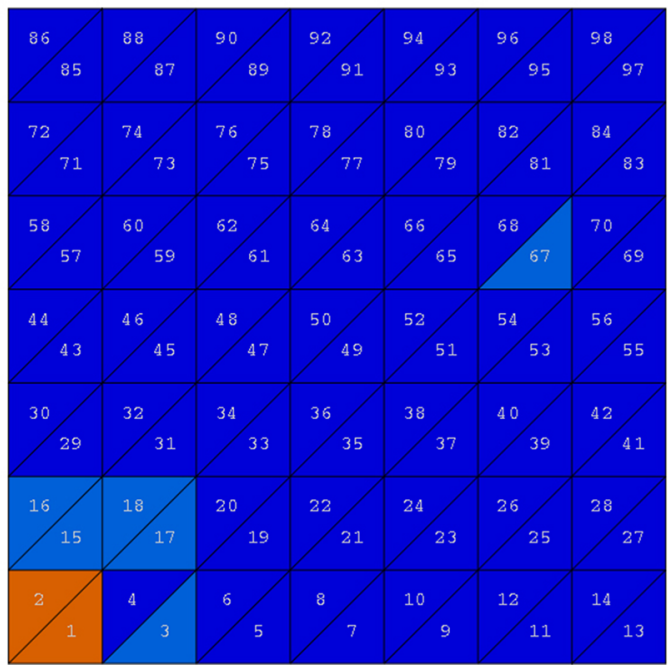

Matrix Compressive Mode

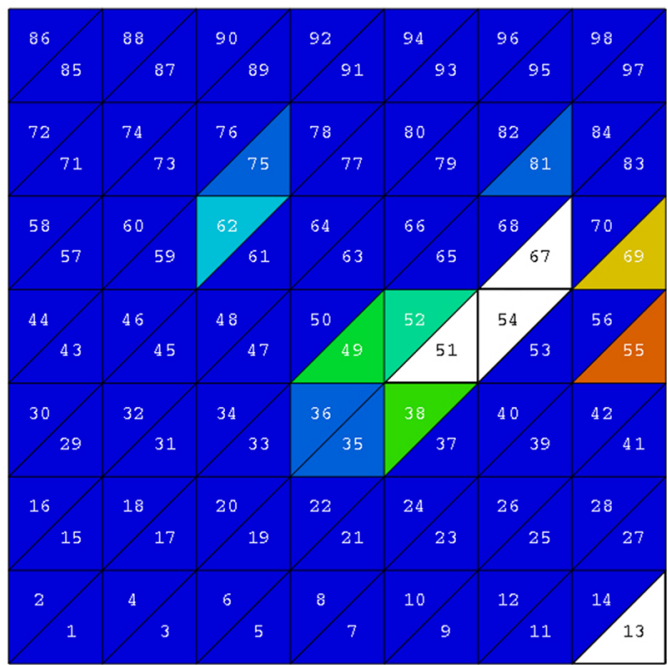

Fibre Compressive Mode

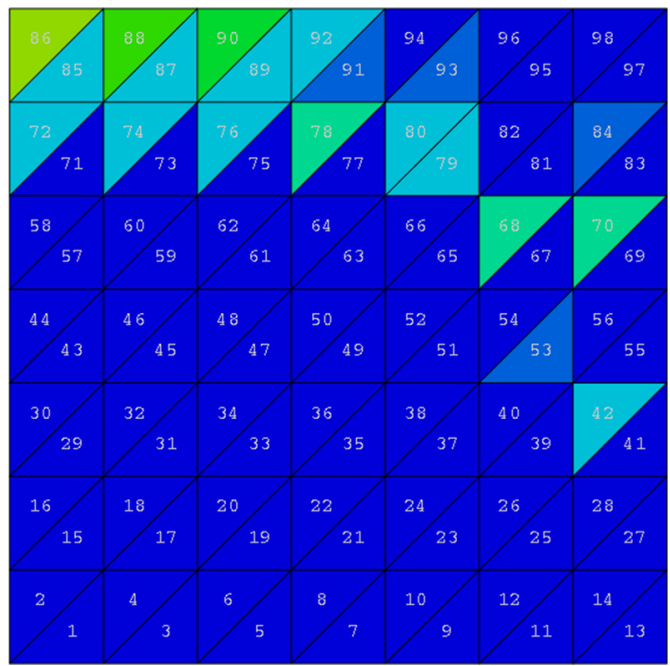

Fig. 6 Problem 1: element-wise indices of Hashin's failure criteria for the principal stress design result in Fig. 3 d. Load $F=20$ N/mm². White elements are failed 


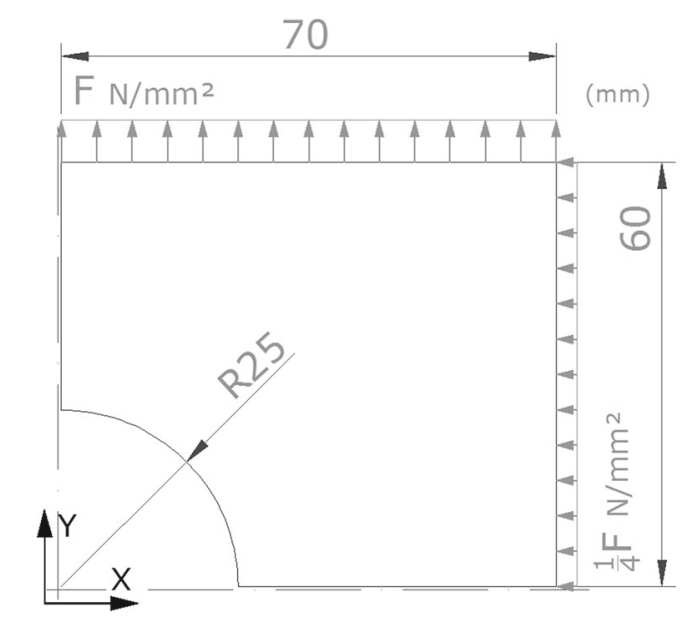

Fig. 7 Problem 2: structure, load and boundary conditions

respectively, evaluated for the optimisation load of $F=$ $20 \mathrm{~N} / \mathrm{mm}^{2}$. In both designs, the carbon-nylon 3DCF material in Table 1 was used. From these plots, it can be seen that in general terms the matrix criteria were improved when HA-OCM was employed in case $(a)$, in comparison with case $(b)$ obtained with principal stress design, since structure $(b)$ failed according to the matrix compressive criterion for the load evaluated. Furthermore, the HA-OCM did not cause problems regarding failure of the fibre modes. This behaviour was also observed for the cases with the $\mathrm{CF}$ and GF materials, where the matrix criteria had their indices minimised, in general terms.

\subsection{Problem 2: Plate with a hole}

A rectangular plate with an inner circular hole was modelled using a one-quarter symmetrical model, as depicted in Fig. 7. It was subjected simultaneously to two uniformly distributed loads: tensile on the outer horizontal edge and compressive on the outer vertical edge. The structure was discretised in ABAQUS using $332 \mathrm{~S} 3 \mathrm{R}$ general shell FE, of thickness $0.51 \mathrm{~mm}$, and optimised for the GF material in Table 1. The load employed was $F=17 \mathrm{~N} / \mathrm{mm}^{2}$, which guaranteed final results without failure according to Hashin's criteria.

Figure 8 shows material orientation results $(a)$, obtained using HA-OCM, and $(b)$, obtained by principal stress design. These designs are plotted alongside maximum principal stresses in absolute (here $\sigma_{1 p}$ ). Figure 9 shows results throughout iterations and convergence for failure load and compliance, and Table 4 shows a summary of the final results. It is seen that final designs differ and, in view of results shown in Table 4, design (a) has a failure load $100 \%$ higher than $(b)$. These results show that the HA-OCM was again able to obtain a design with improved failure load compared with principal stress design.

For design (a), all optimal material orientations ended up either aligned or at $90^{\circ}$ with the maximum absolute principal stress directions, as highlighted in Fig. 8. As commented earlier in Section 5.1, both orientations are possible optimal results, that may minimise the Hashin matrix criteria according to the OC derived in this paper. Design (b) has all optimal material orientations aligned with the
Fig. 8 Problem 2: final design (a), obtained with HA-OCM, and $(b)$, with principal stress design. Orange arrows are maximum principal stresses in absolute $\sigma_{1 p}$. Black lines are local material 1-directions (fibre). In (a), the red circle highlights the occurrence of material oriented at $0^{\circ}$ and $90^{\circ}$ with the principal stress direction at the optimised design, a possible result in HA-OCM.

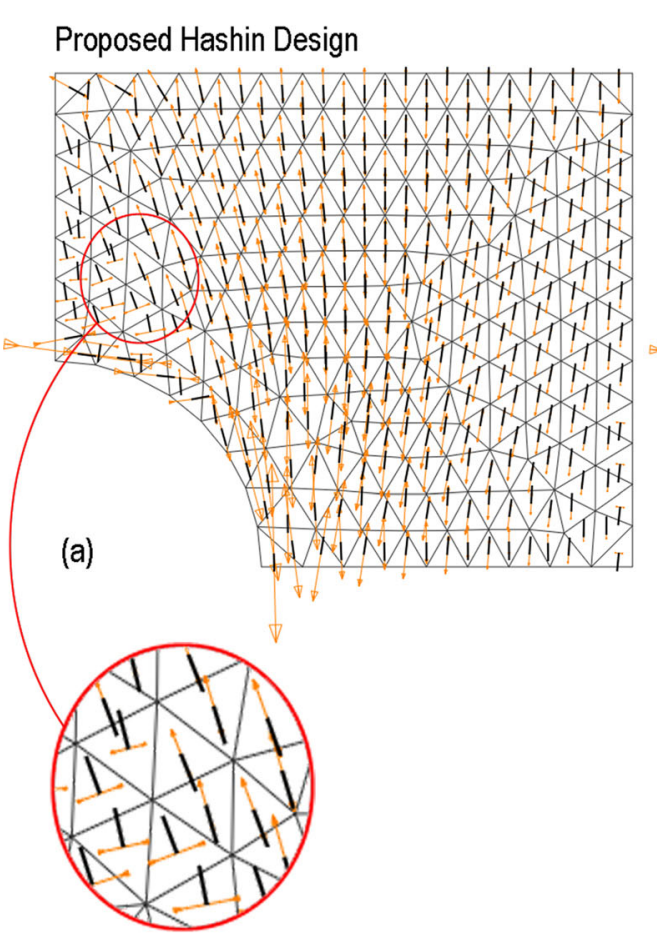

Principal Stress Design

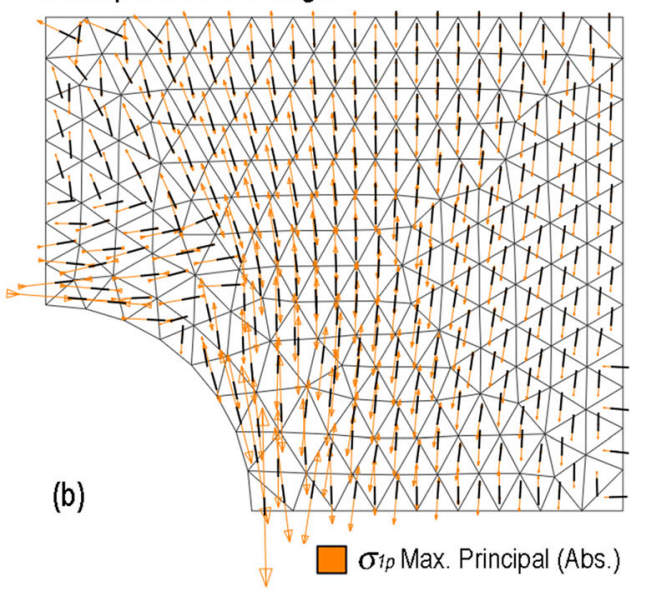



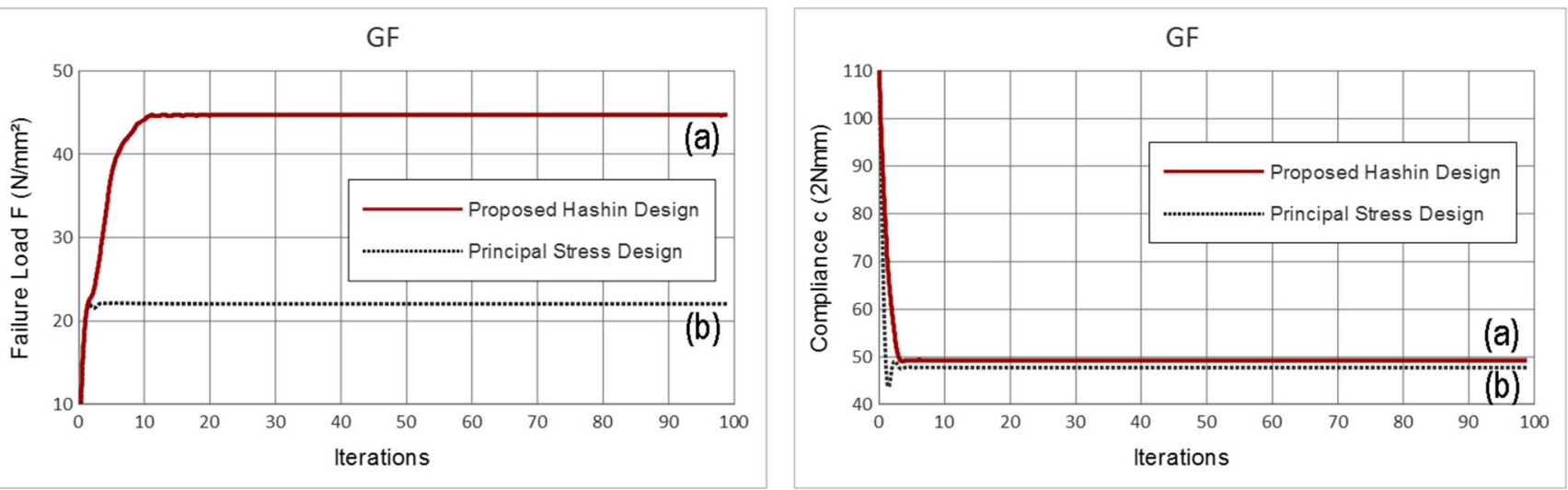

Fig. 9 Problem 2: failure loads and compliance throughout iterations, for cases $(a)$ and $(b)$

maximum absolute principal stress directions, as expected for principal stress design. Both final designs resulted in almost the same compliance, as can be seen from the optimisation behaviour throughout iterations in Fig. 9 and Table 4.

\subsection{Problem 3: Bracket under tensile and compressive loadings}

Figure 10 shows the model of a bracket, considering its horizontal symmetry. It has a hole on the leftmost side and it is clamped on the rightmost edge. Two different loadings were considered, namely tensile and compressive, as shown in upper and lower cases of Fig. 10, respectively. Both tensile and compressive loads were applied to the hole edge with a sinusoidal distribution. They were separately employed in optimisation tests, with a maximum magnitude of $F=20 \mathrm{~N} / \mathrm{mm}^{2}$, which guaranteed final results not failed according to the Hashin's criteria. All cases were represented in ABAQUS by meshes of 1790 S3R general shell elements of thickness $0.51 \mathrm{~mm}$. The material properties of the 3D printed carbon-nylon 3DCF in Table 1 were considered.

Figure 12 shows results in terms of material orientations for cases $(a)$ and $(c)$, subjected to tensile loading, and Fig. 13 for cases $(b)$ and $(d)$, subjected to compressive loading. All designs are plotted alongside maximum principal stresses in absolute (here $\sigma_{1 p}$ ). In both compared pairs, the cases were run with the HA-OCM and principal stress design method. Results in terms of failure loads and compliances are summarised in Table 5 and convergence throughout iterations is shown in Fig. 11.

From Table 5 and Fig. 11, it is possible to see that the HA-OCM rendered results with improved failure loads in comparison with principal stress design, after convergence. Comparing designs $(a)$ and $(c)$, which are the tensile load cases, the gains were about $310 \%$. Comparing designs $(b)$ and $(d)$, which are compressive load cases, the gains were about 140\% (Figs. 12 and 13).

The material orientations of designs obtained by the HA-OCM had the trend to converge to either aligned or at $90^{\circ}$ with the local maximum absolute principal stress direction. Final compliances were similar for cases $(a)$ and $(c)$, whereas case $(b)$ was $30 \%$ higher than case $(d)$. The higher value for case $(b)$ is probably associated to the fact that the proposed optimisation strategy does not guarantee global optima for compliance, as previously discussed in Section 5.1.1.

\subsection{A note on the influence of initial designs}

As stated at the beginning of the current Section 5, all optimal results in Sections 5.1, 5.2 and 5.3 had initial designs in which all elements' material 1-directions were aligned at $0^{\circ}$ to the $X$-axis in Figs.2, 7 and 10, in terms of material orientations.

In order to assess the influence of initial material orientations on HA-OCM, two additional initial designs were tested: every element, material 1-directions at $90^{\circ}$ and $-45^{\circ}$ to the $X$-axis in Figs. 2, 7 and 10. The
Table 4 Problem 2: failure loads and compliance for designs $(a)$ and $(b)$ in Fig. 8, at the final 100th iteration

\begin{tabular}{llllllll}
\hline $\begin{array}{l}\text { Proposed } \\
\text { HA-OCM }\end{array}$ & $\begin{array}{l}\text { Failure load } \\
F^{*}\left(\mathrm{~N} / \mathrm{mm}^{2}\right)\end{array}$ & $\begin{array}{l}\text { Failure } \\
\text { mode }\end{array}$ & $\begin{array}{l}\text { Compliance } \\
c^{*}(2 \mathrm{Nmm})\end{array}$ & $\begin{array}{l}\text { Principal } \\
\text { stress Des. }\end{array}$ & $\begin{array}{l}\text { Failure load } \\
F^{*}\left(\mathrm{~N} / \mathrm{mm}^{2}\right)\end{array}$ & $\begin{array}{l}\text { Failure } \\
\text { mode }\end{array}$ & $\begin{array}{l}\text { Compliance } \\
c^{*}(2 \mathrm{Nmm})\end{array}$ \\
\hline (a) & 44.718 & MT & 49.152 & (b) & 22.060 & MT & 47.673 \\
\hline
\end{tabular}


Fig. 10 Problem 3: structure, boundary conditions and tensile and compressive loadings
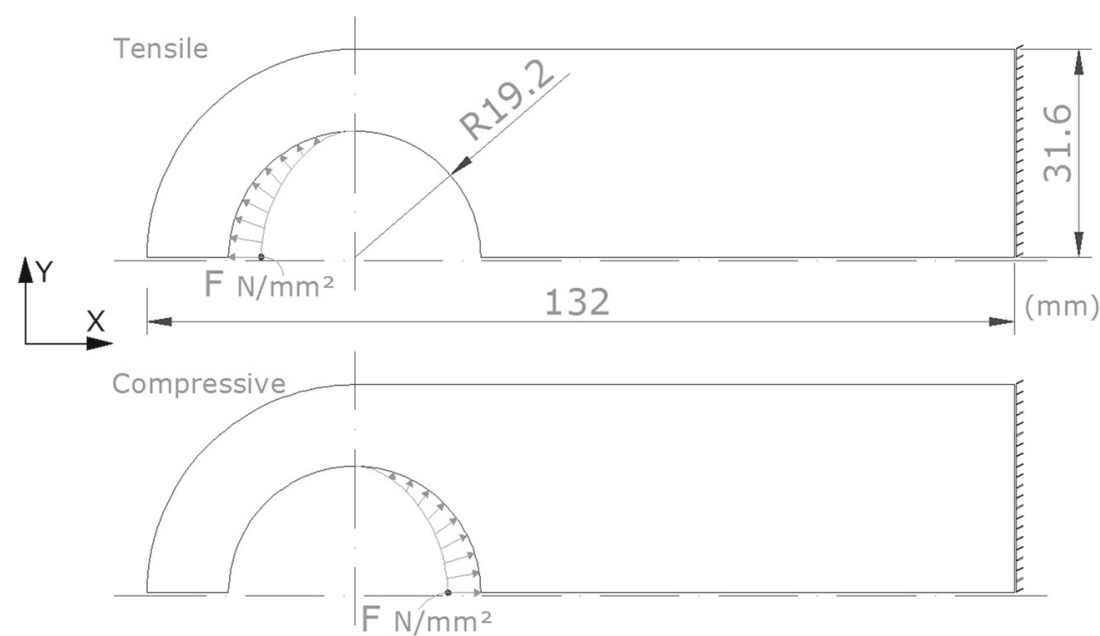

Table 5 Problem 3: failure loads and compliance for designs $(a)$ and $(c)$ in Fig. 12, (b) and $(d)$ in Fig. 13, at the final 100th iteration

\begin{tabular}{llllllll}
\hline $\begin{array}{l}\text { Proposed } \\
\text { HA-OCM }\end{array}$ & $\begin{array}{l}\text { Failure load } \\
F^{*}\left(\mathrm{~N} / \mathrm{mm}^{2}\right)\end{array}$ & $\begin{array}{l}\text { Failure } \\
\text { mode }\end{array}$ & $\begin{array}{l}\text { Compliance } \\
c^{*}(2 \mathrm{Nmm})\end{array}$ & $\begin{array}{l}\text { Principal } \\
\text { stress Des. }\end{array}$ & $\begin{array}{l}\text { Failure load } \\
F^{*}\left(\mathrm{~N} / \mathrm{mm}^{2}\right)\end{array}$ & $\begin{array}{l}\text { Failure } \\
\text { mode }\end{array}$ & $\begin{array}{l}\text { Compliance } \\
c^{*}(2 \mathrm{Nmm})\end{array}$ \\
\hline (a) Tens. & 49.592 & $\mathrm{MC}$ & 20.519 & (c) Tens. & 15.882 & MC & 22.102 \\
(b) Compr. & 40.219 & $\mathrm{MC}$ & 11.228 & (d) Compr. & 28.212 & $\mathrm{MT}$ & 8.553 \\
\hline
\end{tabular}
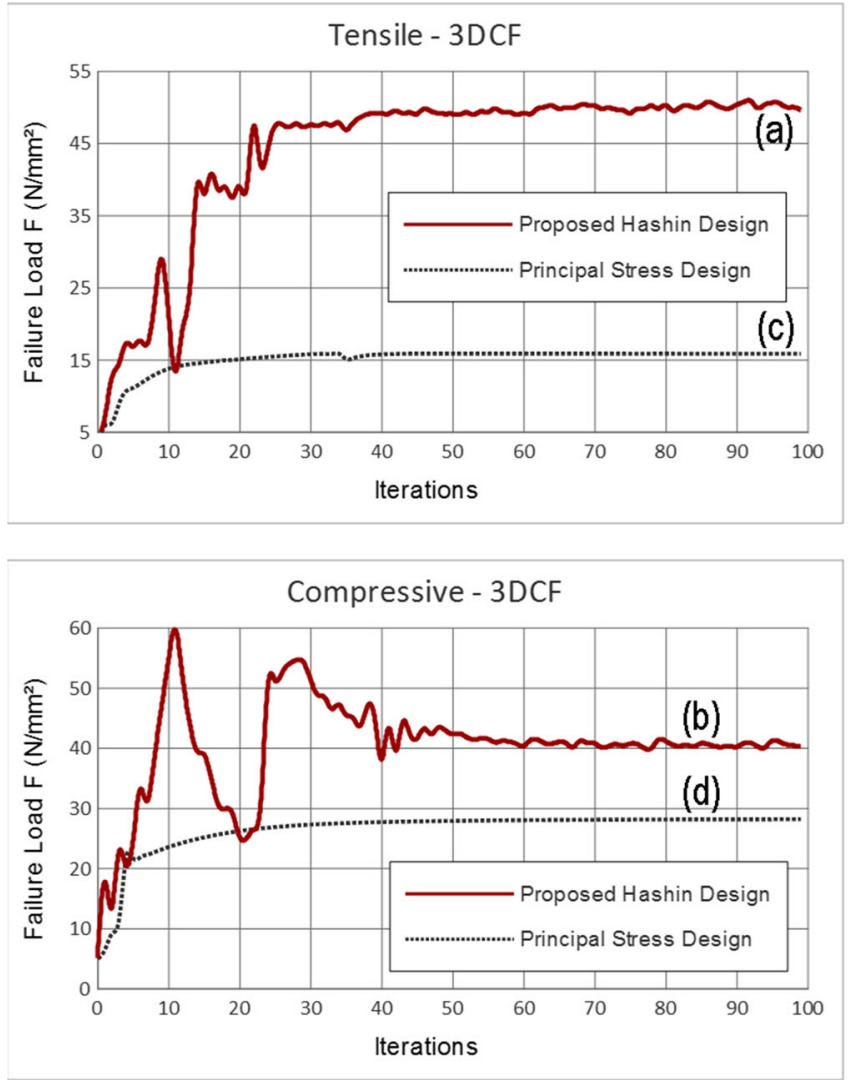
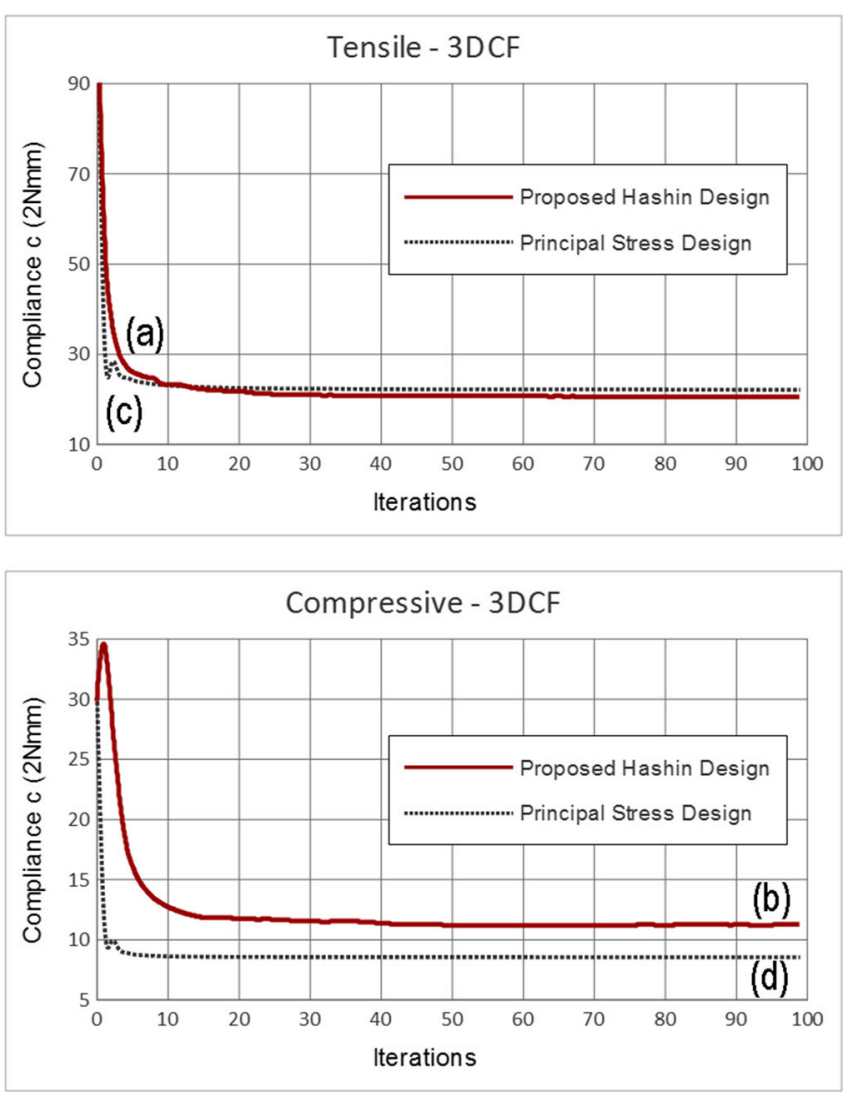

Fig. 11 Problem 3: failure loads and compliance throughout iterations, for cases $(a)$ to $(d)$ 


\section{Tensile Case \\ Proposed Hashin Design}

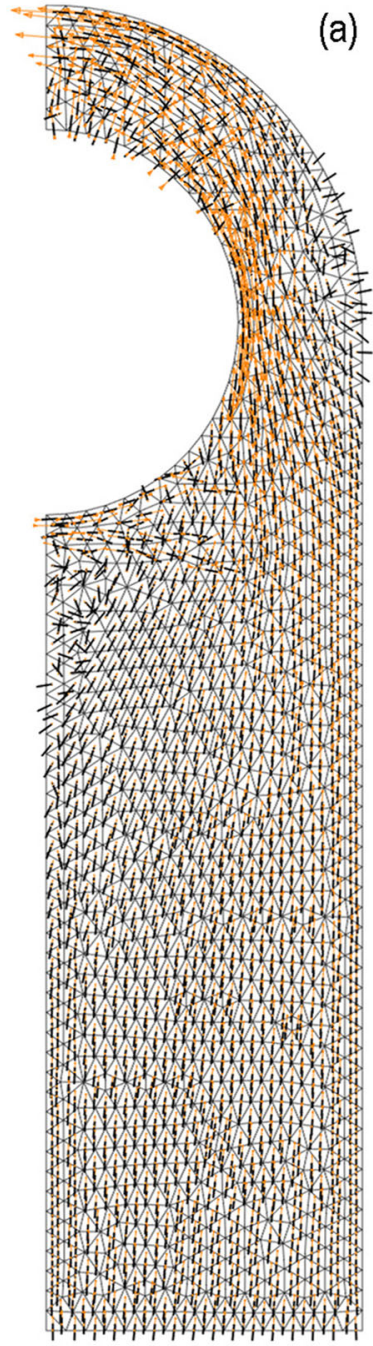

Principal Stress Design

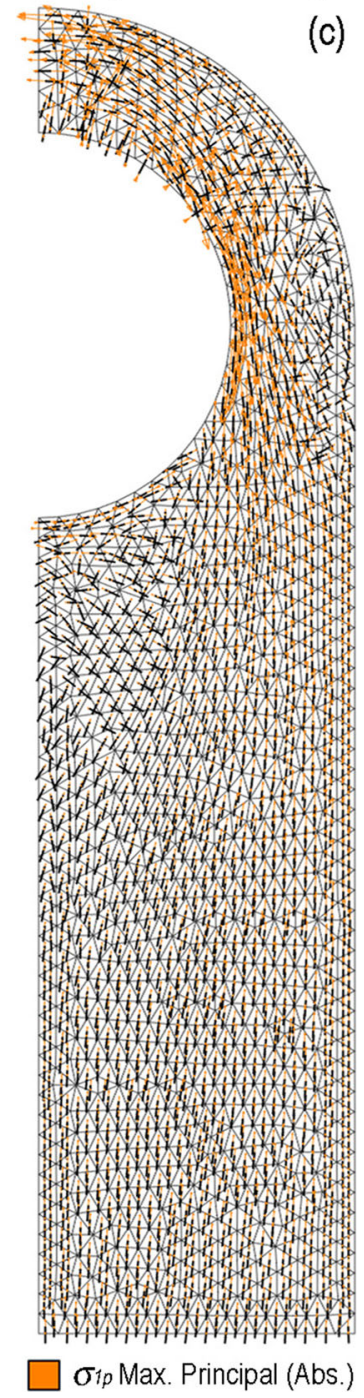

(c)

\section{Compressive Case}

Proposed Hashin Design

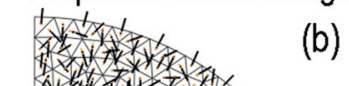

(b)

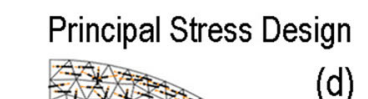

(d)

Fig. 12 Problem 3: tensile case-final design (a) obtained by HAOCM and $(c)$ with principal stress design. Orange arrows are maximum principal stresses in absolute $\sigma_{1 p}$. Black lines are local material 1-directions (fibre)

tests based on these new initial designs indicated that the HA-OCM may be influenced by the initial design configuration, since final results obtained differed from the results in Sections 5.1 to 5.3. In some cases, structures with better failure loads than those presented could be obtained. However, in every additional test performed, the HA-OCM was able to successfully raise the failure loads of the designed structures, using the same 100 iterations as before. This aspect may indicate convergence to different local minima, depending on the starting design for orientations. Therefore, it is advisable to run the HAOCM from more than one starting point for each particular case.
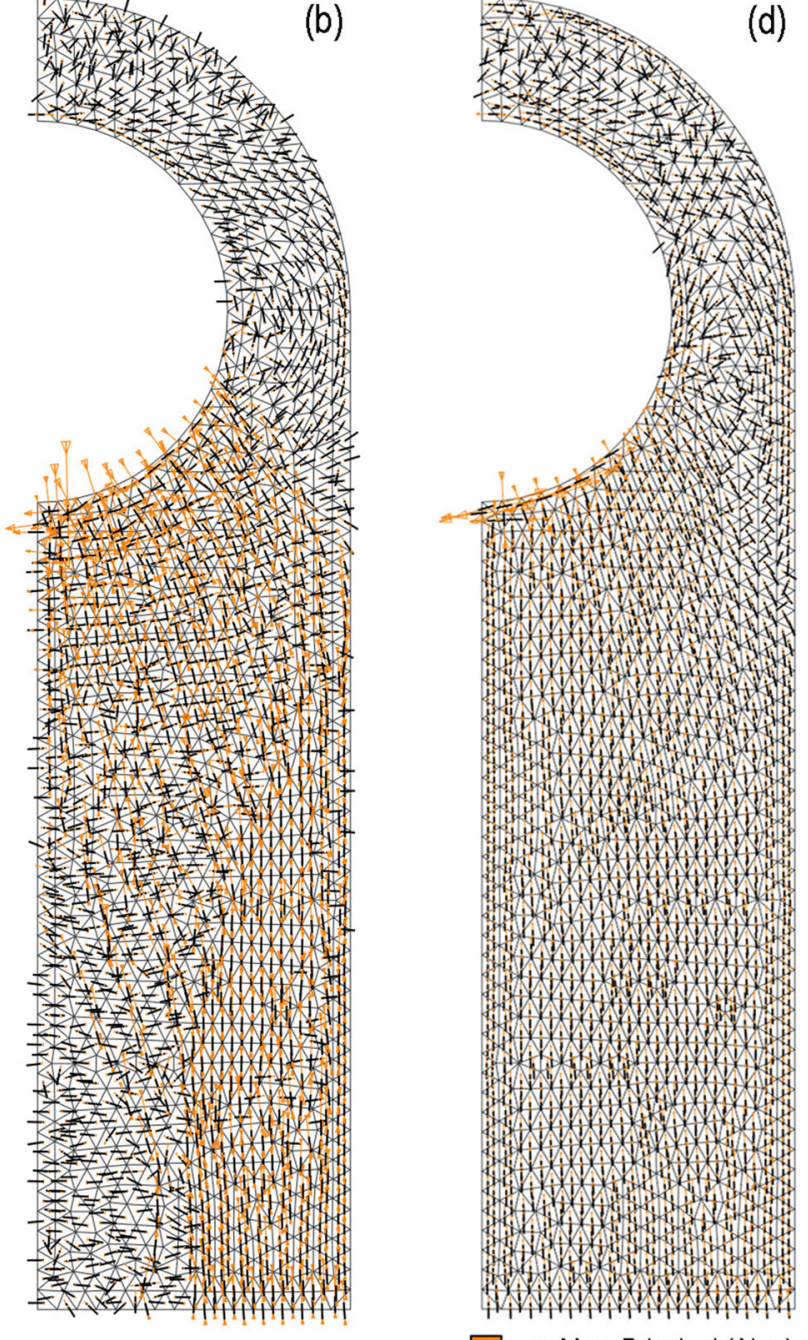

$\sigma_{i p}$ Max. Principal (Abs.)

Fig. 13 Problem 3: compressive case-final design (b) obtained by HA-OCM and $(d)$ with principal stress design. Orange arrows are maximum principal stresses in absolute $\sigma_{1 p}$. Black lines are local material 1-directions (fibre)

\section{Summary and conclusions}

In this work, the optimality conditions of the Hashin's strength criteria were analytically obtained in terms of principal stresses and material strength parameters. The derivations were made separately for each one of the four Hashin's criteria (matrix tensile/compressive, fibre tensile/compressive), following a fixed stress field assumption. From the conditions derived, it was seen that orientations aligned and not aligned with principal stresses may minimise particular failure mode indices. Minimisation when $\sigma_{22} \neq 0$ and $\sigma_{11} \neq 0$ was considered, however the study of cases where Lagrange multipliers $\lambda_{a}$ to $\lambda_{d}$ are not zero may render extra results. 
The optimisation strategy HA-OCM was proposed, based on satisfying the OC for the Hashin's matrix criteria for all elements in a FE mesh representing a structure. It was shown, through a number of test cases over single-layered structures, that the HA-OCM designs had improved failure loads compared with designs generated using the principal stress design method (i.e. fibre orientation following the local maximum in absolute principal stress). Gains in failure loads from 2.7 to $310 \%$ were obtained and, among the test cases here presented, the average gain was $116 \%$. It was shown that 100 iterations were sufficient to attain convergence in the HA-OCM for all test cases. In most cases, convergence was reached in few iterations with instability quickly damping, indicating both the efficiency and robustness of the proposed method, in spite of the fixed stress field hypothesis assumed on the derived OC.

Fibre directions in optimal results had a trend to be either aligned or at $90^{\circ}$ to the local maximum absolute principal stress direction, despite the other possible solutions that minimise the matrix criteria. Albeit this is a condition that possibly minimises compliance (maximises stiffness) of weak in shear (Pedersen 1989) materials, it was shown that both the HA-OCM and principal stress design do not guarantee global minima for compliance, according to the OC in Pedersen $(1989,1990)$.

From the manufacturing point of view, the interpretation of the obtained optimal designs into fibre paths of feasible production is an open challenge. Albeit in several cases design regions present trends on shapes for fibre paths in the presented results, fibre discontinuities and impractical fibre orientation regions may be also seen, as a result of the absence of manufacturing constraints. Further research steps may improve these issues.

Despite the HA-OCM only explicitly satisfying Hashin's matrix criteria, the resulting designs were also satisfied in terms of the fibre strength modes. This point is, however, strongly dependent on loading conditions, and this may be an issue in cases where fibre modes are the most critical. Nevertheless, their OC may also be individually satisfied for such cases in a similar optimisation procedure to that shown here for the matrix modes.

Although the HA-OCM here proposed is simple to apply (arguably due to the fixed stress assumption followed, which guarantees simple analytical solutions for the derived OC), it is shown to be effective in producing designs with failure load improvement by locally minimising the Hashin failure modes indices.

Acknowledgements Special thanks to Prof. Helder C. Rodrigues (Instituto Superior Técnico, University of Lisbon, Portugal) who provided ideas and advice.
Funding information This work was supported by the São Paulo Research Foundation (FAPESP) [grant number 2017/09419-5] and the Engineering and Physical Sciences Research Council [grant number EP/P027261/1].

\section{Compliance with ethical standards}

Conflict of interest The authors declare that they have no conflict of interest.

Replication of results On behalf of the authors, the corresponding author included in the main text of the manuscript the necessary information for replication of the results presented, including OC results and its summary, optimisation algorithm and details on dimensions of structures, loadings, FE meshes and material properties.

Open Access This article is licensed under a Creative Commons Attribution 4.0 International License, which permits use, sharing, adaptation, distribution and reproduction in any medium or format, as long as you give appropriate credit to the original author(s) and the source, provide a link to the Creative Commons licence, and indicate if changes were made. The images or other third party material in this article are included in the article's Creative Commons licence, unless indicated otherwise in a credit line to the material. If material is not included in the article's Creative Commons licence and your intended use is not permitted by statutory regulation or exceeds the permitted use, you will need to obtain permission directly from the copyright holder. To view a copy of this licence, visit http://creativecommons. org/licenses/by/4.0/.

\section{Appendix A: Summary of solutions for Hashin's criteria optimality}

Table 6 shows a summary of all solutions derived for the optimality of Hashin's failure criteria. All solutions presented respect first-order necessary conditions, and then are classified according to their respective second-order sufficiency conditions. Principal stresses $\left|\sigma_{1 p}\right|>\left|\sigma_{2 p}\right|$ are assumed.

The second-order sufficiency condition shown in Table 6 for the matrix tensile criterion solutions $\beta_{Y t 3}^{*}$ and $\beta_{Y t 4}^{*}$ assumes $S_{12}>Y_{t}$ in its derivation. The second-order sufficiency condition in Table 6 for the fibre tensile criterion solutions $\beta_{X t 3}^{*}$ and $\beta_{X t 4}^{*}$ assumes $X_{t}>S_{12}$ in its derivation. Otherwise, all results are general.

\section{A.1 Other solutions to the fibre criteria}

The fibre tensile failure criterion has stationary solutions other than the $\beta_{X t 1}^{*}=0$ shown in Section 3.3. Taking roots of (40), the relevant in terms of material orientations are:

$\beta_{X+2}^{*}=\frac{\pi}{2}$, 
Table 6 Summary of all derived solutions for Hashin's failure criteria optimality

\begin{tabular}{lll}
\hline Solution & 2nd-order sufficient & Comments \\
$\beta^{*}$ & conditions for min. & \\
\hline
\end{tabular}

Matrix tensile (MT) failure criterion, $\sigma_{22}>0\left(\lambda_{a}=0\right)$.

$\begin{array}{ll}\beta_{Y t 1}^{*}=0 & \frac{\sigma_{1 p}-\sigma_{2 p}}{\sigma_{2 p}}+\frac{2 S_{12}^{2}}{Y_{t}^{2}}>0 \\ \beta_{Y t 2}^{*}=\pi / 2 & -\frac{\sigma_{1 p}-\sigma_{2 p}}{\sigma_{1 p}}+\frac{2 S_{12}^{2}}{Y_{t}^{2}}>0 \\ \beta_{Y t 3}^{*}, \beta_{Y t 4}^{*}(16) & {\left[Y_{t}^{2}-2 S_{12}^{2}\right] \frac{\left(\sigma_{1 p}-\sigma_{2 p}\right)^{2}}{\sigma_{1 p} \sigma_{2 p}}-\frac{4 S_{12}^{4}}{Y_{t}^{2}}>0} \\ & \left.\text { (if } S_{12}>Y_{t}\right)\end{array}$

Matrix compressive (MC) failure criterion, $\sigma_{22}<0\left(\lambda_{b}=0\right)$.

$$
\begin{aligned}
& \beta_{Y c 1}^{*}=0 \quad \frac{\left(\sigma_{1 p}-\sigma_{2 p}\right)}{\sigma_{2 p}}+\frac{S_{12}^{2} C_{Y c}}{Y_{c} \sigma_{2 p}}+\frac{S_{12}^{2}}{2 S_{23}^{2}}>0 \quad \text { If min., } \\
& C_{Y c}(22) \\
& \beta_{Y c 2}^{*}=\pi / 2 \quad \frac{\left(\sigma_{1 p}-\sigma_{2 p}\right)}{\sigma_{1 p}}-\frac{S_{12}^{2} C_{Y c}}{Y_{c} \sigma_{1 p}}-\frac{S_{12}^{2}}{2 S_{23}^{2}}>0 \\
& \beta_{Y c 3}^{*}, \beta_{Y c 4}^{*}(30) \quad\left[1-\frac{S_{12}^{2}}{2 S_{23}^{2}}\right] \frac{\left(\sigma_{1 p}-\sigma_{2 p}\right)^{2}}{\sigma_{1 p} \sigma_{2 p}}+ \\
& -\left[\frac{S_{12}^{4}}{2 Y_{c} S_{23}^{2}}\right] \frac{\left(\sigma_{1 p}+\sigma_{2 p}\right)}{\sigma_{1 p} \sigma_{2 p}}-\frac{S_{12}^{4} C_{Y c}^{2}}{Y_{c}^{2} \sigma_{1 p} \sigma_{2 p}}-\frac{S_{12}^{4}}{4 S_{23}^{4}}>0 \quad \text { and } \beta_{Y c 1}^{*}, \beta_{Y c 2}^{*} \max .
\end{aligned}
$$

complex $\beta_{Y t 3}^{*}, \beta_{Y t 4}^{*}$

If min.,

complex $\beta_{Y t 3}^{*}, \beta_{Y t 4}^{*}$

If not complex, $\min$. and $\beta_{Y t 1}^{*}, \beta_{Y t 2}^{*} \max$.

Fibre tensile (FT) failure criterion, $\sigma_{11}>0\left(\lambda_{c}=0\right)$.

$$
\begin{array}{ll}
\beta_{X t 1}^{*}=0 & \frac{\sigma_{1 p}-\sigma_{2 p}}{\sigma_{1 p}}-\frac{2 S_{12}^{2}}{X_{t}^{2}}>0 \\
\beta_{X t 2}^{*}=\pi / 2 & \frac{\sigma_{1 p}-\sigma_{2 p}}{\sigma_{2 p}}+\frac{2 S_{12}^{2}}{X_{t}^{2}}>0 \\
\beta_{X t 3}^{*}, \beta_{X t 4}^{*}(55) & -\left[X_{t}^{2}-2 S_{12}^{2}\right] \frac{\left(\sigma_{1 p}-\sigma_{2 p}\right)^{2}}{\sigma_{1 p} \sigma_{2 p}}+\frac{4 S_{12}^{4}}{X_{t}^{2}}>0 \\
& \text { (if } \left.X_{t}>S_{12}\right)
\end{array}
$$

If $X_{t}>S_{12}$ and $\sigma_{2 p}$ does not approach $\sigma_{1 p}$, min.

Fibre compressive (FC) failure criterion, $\sigma_{11}<0\left(\lambda_{d}=0\right)$.

$$
\begin{array}{lll}
\beta_{X c 1}^{*}=0 & \sigma_{1 p}-\sigma_{2 p}>0 & \text { If } \sigma_{1 p}<0, \max . \\
& \left|\sigma_{1 p}\right|>\left|\sigma_{2 p}\right| & \\
\beta_{X c 2}^{*}=\pi / 2 & \sigma_{2 p}-\sigma_{1 p}>0 & \text { If } \sigma_{1 p}<0, \min . \\
& \left|\sigma_{1 p}\right|>\left|\sigma_{2 p}\right| &
\end{array}
$$

and $\beta_{X t 1}^{*}, \beta_{X t 2}^{*} \min$.
$\beta_{X t 3}^{*}=\frac{\pi}{2}+\frac{1}{2} \arccos \left(Q_{X t}\right), \quad \beta_{X t 4}^{*}=\frac{\pi}{2}-\frac{1}{2} \arccos \left(Q_{X t}\right)$,

where $Q_{X t}=\frac{S_{12}^{2}\left(\sigma_{1 p}+\sigma_{2 p}\right)}{\left(S_{12}^{2}-X_{t}^{2}\right)\left(\sigma_{1 p}-\sigma_{2 p}\right)}$.

The solutions in (55) are valid design orientations when $\left(S_{12}^{2}-X_{t}^{2}\right)\left(\sigma_{1 p}-\sigma_{2 p}\right) \neq 0$, and non-complex when:

$-1<Q_{X t}<1$.

By using similar arguments as in Sections 3.1 and 3.2, it can be shown that the conditions in (57) are related to the second-order sufficient conditions for solutions $\beta_{X t 1}^{*}$ to $\beta_{X t 4}^{*}$, in view of (41), as commented on Table 6.
The fibre compressive failure criterion has $\beta_{X c 2}^{*}=\pi / 2$ as another stationary solution which is relevant in terms of material orientation, except the $\beta_{X c 1}^{*}=0$ shown in Section 3.4.

\section{Appendix B: Summary of Pedersen's optimality criteria for compliance}

According to Pedersen (1989, 1990), local material orientations can be evaluated for their influence on compliance optimal values of structures, based on a material parameter $\alpha_{3}$ and an optimisation parameter $\gamma$.

The material parameter $\alpha_{3}$ is defined by:

$\alpha_{3}=1+\left(E_{2} / E_{1}\right)\left(1-2 v_{12}\right)-4\left(G_{12} / E_{1}\right)\left(1-v_{12} v_{21}\right)$. 
Based on (58), a particular material is classified as weak in shear if $\alpha_{3}>0$. From material properties in Table 1, the carbon-nylon 3DCF has $\alpha_{3}=0.966$, the carbon-epoxy CF has $\alpha_{3}=0.877$ and the glass-epoxy GF has $\alpha_{3}=0.722$. Therefore, they are all weak in shear.

The optimisation parameter $\gamma$ is defined as:

$\gamma=\left[\frac{\left(C_{11}-C_{22}\right)}{\left(C_{11}+C_{22}\right)-2\left(C_{12}-2 C_{66}\right)}\right]\left(\frac{1+\epsilon_{2 p} / \epsilon_{1 p}}{1-\epsilon_{2 p} / \epsilon_{1 p}}\right)$.

In (59), the $C_{11}, \ldots, C_{66}$ for a single-layered orthotropic material are given by:

$C_{11}=\frac{E_{1}}{1-v_{12} v_{21}}, \quad C_{12}=\frac{v_{12} E_{2}}{1-v_{12} v_{21}}$,

$C_{22}=\frac{E_{2}}{1-v_{12} v_{21}}, \quad C_{66}=G_{12}$,

and $\epsilon_{1 p}, \epsilon_{2 p}$ are in-plane principal strains where $\left|\epsilon_{1 p}\right|>$ $\left|\epsilon_{2 p}\right|$. It is here defined $\phi$ as the angle from principal strain $I$-direction to the local material 1-direction.

Following Pedersen $(1989,1990)$, when $\alpha_{3}>0$ and $0<\gamma<1$, for compliance:

$\phi=0^{\circ}$ is a global minimum,

$\phi= \pm 90^{\circ}$ is a local minimum,

$\cos 2 \phi=-\gamma$ is a local maximum.

Moreover, when $\alpha_{3}>0$ and $\gamma>1$, for compliance:

$\phi=0^{\circ}$ is a global minimum and

$\phi= \pm 90^{\circ}$ is a global maximum.

These are the conditions evaluated to compose Table 3 in Section 5.1.

\section{References}

Abdalla MM, Setoodeh S, Gürdal Z (2007) Design of variable stiffness composite panels for maximum fundamental frequency using lamination parameters. Compos Struct 81(2):283-291

Barbero EJ (2010) Introduction to composite materials design, 2nd edn. CRC Press, Boca Raton. ISBN 1420079158,9781420079159

Bendsøe MP, Sigmund O (2003) Topology optimization: Theory, methods and applications, 2nd edn. Springer, Berlin. ISBN 3-54042992-1

Boisse P, Hamila N, Helenon F, Aimene $\mathrm{Y}$, Mabrouki $\mathrm{T}$ (2007) Draping of textile composite reinforcements: Continuous and discrete approaches. Adv Compos Lett 16:999-1010. https://doi.org/10.1177/096369350701600401

Brampton CJ, Wu KC, Kim AH (2015) New optimization method for steered fiber composites using the level set method. Struct Multidiscip Optim 52(3):493-505. https://doi.org/10.1007/s00158-0151256-6

Brandmaier HE (1970) Optimum filament orientation criteria. J Compos Mater 4:422-425. https://doi.org/10.1177/002199837000400 314
Brüyneel M (2011) SFP - a new parameterization based on shape functions for optimal material selection: Application to conventional composite plies. Struct Multidiscip Optim 43:17-27. https://doi.org/10.1007/s00158-010-0548-0

Cherouat A, Borouchaki H, Billoët J-L (2005) Geometrical and mechanical draping of composite fabric. Revue Européenne des Eléments Finis, Hermès 14(6-7):693-707. ff10.3166/reef.14.693707ff source: https://hal.archives-ouvertes.fr/hal-00020293

Christensen RM (2014) Timoshenko medal award paper - completion and closure on failure criteria for unidirectional fiber composite materials. J Appl Mech 81(011011):1-6. https://doi.org/10.1115/ 1.4025177

Crosky A, Kelly D, Li R, Legrand X, Huong N, Ujjin R (2006) Improvement of bearing strength of laminated composites. Compos Struct 76:260-271. https://doi.org/10.1016/j.compstruct. 2006.06.036

Dai J, Hahn HT (2003) Flexural behavior of sandwich beams fabricated by vacuum-assisted resin transfer molding. Compos Struct 61(3):247-253. https://doi.org/10.1016/S0263-8223(03)00040-0

de Miguel AG, Kaleel I, Nagaraj MH, Pagani A, Petrolo M, Carrera E (2018) Accurate evaluation of failure indices of composite layered structures via various FE models. Compos Sc Technol 167:174-189. https://doi.org/10.1016/j.compscitech.2018.07.031

Dickson AN, Barry JN, McDonnell KA, Dowling DP (2017) Fabrication of continuous carbon, glass and Kevlar fibre reinforced polymer composites using additive manufacturing. Additive Manufacturing 16:146-152. https://doi.org/10.1016/j.addma. 2017.06.004

Dutra TA, Ferreira RTL, Resende HB, Guimarães A (2019) Mechanical characterization and asymptotic homogenization of 3D-printed continuous carbon fiber-reinforced thermoplastic. J Brazilian Soc Mech Sci Engineer 41(3):133. https://doi.org/10.1007/s40430019-1630-1

Ferreira R, Ashcroft I, Zhuo P, Li S (2018) Optimisation of fibre-paths in composites produced by additive manufacturing. Proceedings of the 6th international conference on engineering optimization, EngOpt2018, Lisbon, Portugal 17-19th September. https://doi.org/10.1007/978-3-319-97773-7-94

Ferreira RTL, Amatte IC, Dutra TA, Bürger D (2017) Experimental characterization and micrography of 3D printed PLA and PLA reinforced with short carbon fibers. Compos Part B: Engineer 124:88-100. https://doi.org/10.1016/j.compositesb.2017.05.013

Ferreira RTL, Donadon MV, Hernandes JA (2011) Structural optimization of a composite plate subjected to a small mass impact. Journal of Material Science and Engineering B 1:536-550

Ferreira RTL, Hernandes JA (2015) Advanced approximations for sequential optimization with discrete material interpolations. Struct Multidiscip Optim 51(6):1305-1320. https://doi.org/10. 1007/s00158-014-1216-6

Ferreira RTL, Rodrigues HC, Guedes JM, Hernandes JA (2014) Hierarchical optimization of laminated fiber reinforced composites. Compos Struct 107(1):246-259. https://doi.org/10.1016/j. compstruct.2013.07.051

Foldager J, Hansen JS, Olhoff N (1998) A general approach forcing convexity of ply angle optimization in composite laminates. Structural Optimization 16(2-3):201-211. https://doi.org/10.1007/ BF01202831

Fukunaga H, Vanderplaats GN (1991) Strength optimization of laminated composites with respect to layer thickness and/or layer orientation angle. Comput Struct. 40(6):1429-1439. https://doi.org/ 10.1016/0045-7949(91)90413-G

Gao T, Zhang T, Duysinx P (2012) A bi-value coding parameterization scheme for the discrete optimal orientation design of the composite laminate. International Journal for Numerical Methods in Engineering 91(1):98-114. https://doi.org/10.1002/nme. 4270 
Ghiasi H, Fayazbakhsh K, Pasini D, Lessard L (2010) Optimum stacking sequence design of composite materials Part II: Variable stiffness design. Compos Struct 93:1-13. https://doi.org/10.1016/j. compstruct.2010.06.001

Ghiasi H, Pasini D, Lessard L (2009) Optimum stacking sequence design of composite materials Part I: Constant stiffness design. Compos Struct 90:1-11. https://doi.org/10.1016/j.compstruct. 2009.01.006

Groenwold AA, Haftka RT (2006) Optimization with non-homogeneous failure criteria like Tsai-Wu for composite laminates. Struct Multidiscip Optim 32:183-190. https://doi.org/10. 1007/s00158-006-0020-3

Hammer VB, Pedersen PBestle D, Schiehlen W (eds) (1996) Optimization of Laminate Strength. Springer, Dordrecht. https://doi.org/10.1007/978-94-009-0153-7

Hashin Z (1980) Failure criteria for unidirectional fiber composites. J Appl Mech 47(2):329-334. https://doi.org/10.1115/1.3153664

Hashin Z, Rotem A (1973) A fatigue failure criterion for fiber reinforced materials. J Compos Mater 7:448-464. https://doi.org/10. $1177 / 002199837300700404$

Hohe J, Becker W (2002) Optimized structural sandwich panels with minimum delamination hazards. Struct Multidiscip Optim 23(6):448-459. https://doi.org/10.1007/s00158-002-0206-2

Hu H-T (1994) Buckling optimization of fiber-composite laminate shells considering in-plane shear nonlinearity. Structural Optimization 8:168-173. https://doi.org/10.1007/BF01743314

Hyer MW, Charette RF (1987) Innovative design of composite structures: Use of curvilinear fiber format to improve structural efficiency. Technical Report NASA-CR-180967. ntrs.nasa.gov/ search.jsp?R=19870016936

Sloan J (2008) ATL and AFP: Defining the megatrends in composite aerostructures. Composites World. 7. https://www. compositesworld.com/articles/atl-and-afp-defining-the-megatrendsin-composite-aerostructures

Jones RM (1998) Mechanics Of composite materials, 2nd edn. CRC Press, Boca Raton. ISBN 156032712X, 9781560327127

Joosten MW (2019) An enhanced ply damage model for failure prediction in unidirectional composite structures. Compos Struct 207:752-763. https://doi.org/10.1016/j.compstruct.2018.09. 039

Karakaya Ş, Soykasap Ö (2011) Natural frequency and buckling optimization of laminated hybrid composite plates using genetic algorithm and simulated annealing. Struct Multidiscip Optim 43(1):61-72. https://doi.org/10.1007/s00158-010-0538-2

Kathiravan R, Ganguli R (2007) Strength design of composite beam using gradient and particle swarm optimization. Compos Struct 81:471-479. https://doi.org/10.1016/j.compstruct.2006.09.007

Kaveh A, Dadras A, Geran Malek N (2019) Robust design optimization of laminated plates under uncertain bounded buckling loads. Struct Multidiscip Optim 59(3):877-891. https://doi.org/10.1007/ s00158-018-2106-0

Kelly P (2015) Solid mechanics part I: An introduction to solid mechanics. http://homepages.engineering.auckland.ac.nz/ $\sim$ pkel015

Kim D-H, Kim S-W (2019) Evaluation of bird strike-induced damages of helicopter composite fuel tank assembly based on fluid-structure interaction analysis. Compos Struct 210:676-686. https://doi.org/10.1016/j.compstruct.2018.11.086

Kiyono CY, Silva ECN, Reddy JN (2017) A novel fiber optimization method based on normal distribution function with continuously varying fiber path. Compos Struct 160:503-515. https://doi.org/10.1016/j.compstruct.2016.10.064

Koh R, Madsen B (2018) Strength failure criteria analysis for a flax fibre reinforced composite. Mech Mater 124:26-32. https://doi.org/10.1016/j.mechmat.2018.05.005
Koide RM, Luersen MA (2013) Maximization of fundamental frequency of laminated composite cylindrical shells by ant colony algorithm. Journal of Aerospace Technology and Management 5(1). https://doi.org/10.5028/jatm.v5i1.233

Kriechbaum R, Schafer J, Mattheck M (1992) CAIO (computer aided internal optimisation): A powerful method to optimise fiber arrangement in composites. In: 1st European conference on smart structures and materials, Glasgow. 281-284. https://doi.org/10.1117/12.2298080

Lemaire E, Zein S, Brüyneel M. (2015) Optimization of composite structures with curved fiber trajectories. Compos Struct 131:895904. https://doi.org/10.1016/j.compstruct.2015.06.040

Li X, Ma D, Liu H, Tan W, Gong X, Zhang C, Li Y (2019) Assessment of failure criteria and damage evolution methods for composite laminates under low-velocity impact. Compos Struct 207:727-739. https://doi.org/10.1016/j.compstruct.2018.09. 093

Lindgaard E, Lund E (2011) Optimization formulations for the maximum nonlinear buckling load of composite structures. Struct Multidiscip Optim 43(5):631-646. https://doi.org/10.1007/s00158010-0593-8

Lukaszewicz DHJ, Ward C, Potter KD (2012) The engineering aspects of automated prepreg layup: History, present and future. Compos Part B: Engineer 43(3):997-1009. https://doi.org/10.1016/j. compositesb.2011.12.003

Lund E (2009) Buckling topology optimization of laminated multimaterial composite shell structures. Compos Struct 91:158-157. https://doi.org/10.1016/j.compstruct.2009.04.046

Lund E (2017) Discrete material and thickness optimization of laminated composite structures including failure criteria. Structural and Multidisciplinary Optimization. https://doi.org/10.1007/s00158017-1866-2

Lund E, Stegmann J (2005) On structural optimization of composite shell structures using a discrete constitutive parametrization. Wind Energy 8(1):109-124. https://doi.org/10.1002/we.132

Magagnato D, Seuffert J, Bernath A, Kärger L, Henning F (2018) Experimental and numerical study of the influence of integrated load transmission elements on filling behavior in resin transfer molding. Compos Struct 198:135-143. https://doi.org/10.1016/j. compstruct.2018.05.021

Majak J, Hannus S (2003) Orientational design of anisotropic material using the Hill and Tsai-Wu strength criteria. Mech Compos Mater 39(6):509-520. https://doi.org/10.1023/B:MOCM.0000010623. $38596.3 \mathrm{e}$

Majak J, Pohlak M (2010) Optimal material orientation of linear and non-linear elastic 3D anisotropic materials. Meccanica 45:671680. https://doi.org/10.1007/s11012-009-9262-7

Malakhov AV, Polilov AN (2016) Design of composite structures reinforced curvilinear fibres using FEM. Composites: Part A 87:23-28. https://doi.org/10.1016/j.compositesa.2016.04.005

Masur EF (1970) Optimum stiffness and strength of elastic structures. J Engineer Mech Div 96(5):621-640

Matsuzaki R, Ueda M, Namiki M, Jeong T.-K., Asahara H, Horiguchi K, Nakamura T, Todoroki A, Hirano Y (2016) Threedimensional printing of continuous-fiber composites by in-nozzle impregnation. Scientific Reports 6:23058. https://doi.org/10.1038/ srep23058

Montemurro M, Catapano A (2017) On the effective integration of manufacturability constraints within the multi-scale methodology for designing variable angle-tow laminates. Compos Struct 161:145-159. https://doi.org/10.1016/j.compstruct.2016.11.018

Muramatsu Y, Shimoda M (2019) Distributed-parametric optimization approach for free-orientation of laminated shell structures with anisotropic materials. Struct Multidiscip Optim 59(6):1915-1934. https://doi.org/10.1007/s00158-018-2163-4 
Nicoloso LV (2018) Optimization of varying orientation of continuous fiber direction and its applications to new methods of additive manufacturing, vol 3. https://doi.org/10.31031/RDMS.2018.03. 000559

París F (2001) A study of failure criteria of fibrous composite materials. Technical Report NASA/CR-2001-210661. ntrs.nasa. gov/search.jsp?R=20010035883

Park JH, Hwang JH, Lee CS, Hwang W (2001) Stacking sequence design of composite laminates for maximum strength using genetic algorithms. Compos Struct 52(2):217-231. https://doi.org/ 10.1016/S0263-8223(00)00170-7

Pedersen P (1989) On optimal orientation of orthotropic materials. Structural Optimization 1:101-106. https://doi.org/10.1007/ BF01637666

Pedersen P (1990) Bounds on elastic energy in solids of orthotropic materials. Struct Optim 2:55-63. https://doi.org/10.1007/BF017 43521

Pedersen P (1991) On thickness and orientational design with orthotropic materials. Struct Optim 3:69-78. https://doi.org/10. 1007/BF01743275

Pedersen P (1998) Some general optimal design results using anisotropic, power law nonlinear elasticity. Struct Multidiscip Optim 15:73-80. https://doi.org/10.1007/BF01278492

Pedersen P (2004) Examples of density, orientation, and shape-optimal 2D-design for stiffness and/or strength with orthotropic materials. Struct Multidiscip Optim 26:37-49. https://doi.org/10.1007/ s00158-003-0295-6

Puck A, Schürmann H (1998) Failure analysis of FRP laminates by means of physically based phenomenological models. Compos Sci Technol 58:1045-1067. https://doi.org/10.1016/S0266-3538(01) 00208-1

Reuschel D, Mattheck C (1999) Optimization of fiber arrangement with CAIO (computer aided internal optimization) and application to tensile samples. Transactions on the Built Environment 36:247255. ISSN 1743-3509

Rovati M, Taliercio A (1991) Optimal orientation of the symmetry axes of orthotropic 3-D materials. In: Eschenauer HA, Mattheck C, Olhoff N (eds) Engineering optimization in design processes. Lecture Notes in Engineering. 63, 127-134. Springer. https://doi.org/10.1007/978-3-642-84397-6-12

Schmit LA, Farshi B (1973) Optimum laminate design for strength and stiffness. Int J Numer Methods Eng 7(4):519-536. https://doi.org/10.1002/nme.1620070410

Seregin GA, Troitskii VA (1981) On the best position of elastic symmetry planes in an orthotropic body. J Appl Math Mech 45(1):139-142. https://doi.org/10.1016/0021-8928(81)90022-8

Setoodeh S, Abdalla MM, Gürdal Z. (2006) Design of variablestiffness laminates using lamination parameters. Composites Part B: Engineer. 37(4-5):301-309. https://doi.org/10.1016/j. compositesb.2005.12.001
Soden PD, Hinton MJ, Kaddour AS (1998) Lamina properties, layup configurations and loading conditions for a range of fibrereinforced composite laminates. Compos Sci Technol 58:10111022. https://doi.org/10.1016/S0266-3538(98)00078-5

Tan SC (1994) Stress concentrations in laminated composites. Taylor and Francis. ISBN 1-56676-077-1

Taylor JE (1969) Maximum strength elastic structural design. J Engineer Mech Div 95(3):653-66

Topal U, Uzman Ü (2008) Strength optimization of laminated composite plates. J Compos Mater 42(17):1731-1746. https://doi.org/10. $1177 / 0021998308093368$

Tosh MW, Kelly DW (2000) On the design, manufacture and testing of trajectorial fibre steering for carbon fibre composite laminates. Composites: Part A 31:1047-1060. https://doi.org/10.1016/ S1359-835X(00)00063-4

Trinh KV (1997) Modeling the in-plane tension failure of composite plates. Sandia Report SAND97-8001 US-406

Tsai SW, Wu EM (1971) A general theory of strength for anisotropic materials. J Compos Mater 5:58-80. https://doi.org/10.1177/ 002199837100500106

Tsai SW (1965) Strength characteristics of composite materials. Report NASA CR-224. https://ntrs.nasa.gov/search.jsp? $\mathrm{R}=19650012040$

Wang X, Jiang M, Zhou Z, Gou J, Hui D (2017) 3D printing of polymer matrix composites: A review and prospective. Composites Part B 110:442-458. https://doi.org/10.1016/j.compositesb.2016.11.034

Woigk W, Hallett SR, Jones MI, Kuhtz M, Hornig A, Gude M (2018) Experimental investigation of the effect of defects in automated fibre placement produced composite laminates. Compos Struct 201:1004-1017. https://doi.org/10.1016/j.compstruct.2018. 06.078

Yamanaka Y, Todoroki A, Ueda M, Hirano Y, Matsuzaki R (2016) Fiber line optimization in single ply for 3D printed composites. Open J Compos Mater 6:121-131. https://doi.org/10.4236/ojcm. 2016.64012

Yang C, Tian X, Liu T, Cao Y, Li D (2017) 3D printing for continuous fiber reinforced thermoplastic composites: Mechanism and performance. Rapid Prototyping Journal 23(1):209-215. https://doi.org/10.1108/RPJ-08-2015-0098

Zhu Y, Liu J, Liu D, Xu H, Yan C, Huang B, Hui D (2017) Fiber path optimization based on a family of curves in composite laminate with a center hole. Composites Part B 111:91-112. https://doi.org/10.1016/j.compositesb.2016.11.051

Zhuo P, Li S, Ashcroft I, Jones A, Pu J (2017) 3D printing of continuous fibre reinforced thermoplastic composites. In: Proceedings of the 21st International Conference on Composite Materials, ICCM21, ID. 4265, Xi' an, China, 20-25th August

Publisher's note Springer Nature remains neutral with regard to jurisdictional claims in published maps and institutional affiliations. 